\title{
EISA 432 Energy Audits Best Practices: Software Tools
}

\author{
Maryl D. Fisher
}

November 2014

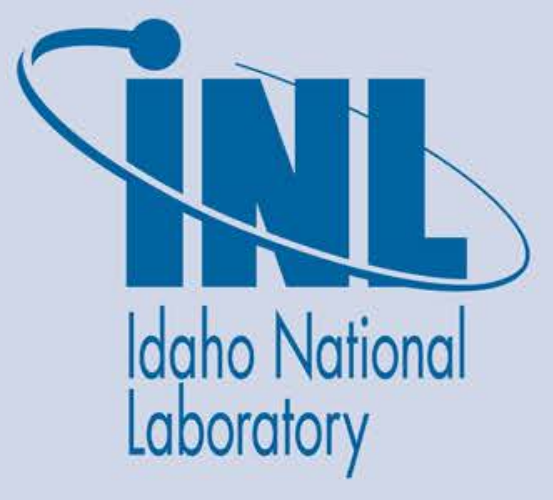

The INL is a U.S. Department of Energy National Laboratory operated by Battelle Energy Alliance 


\section{DISCLAIMER}

This information was prepared as an account of work sponsored by an agency of the U.S. Government. Neither the U.S. Government nor any agency thereof, nor any of their employees, makes any warranty, expressed or implied, or assumes any legal liability or responsibility for the accuracy, completeness, or usefulness, of any information, apparatus, product, or process disclosed, or represents that its use would not infringe privately owned rights. References herein to any specific commercial product, process, or service by trade name, trade mark, manufacturer, or otherwise, does not necessarily constitute or imply its endorsement, recommendation, or favoring by the U.S. Government or any agency thereof. The views and opinions of authors expressed herein do not necessarily state or reflect those of the U.S. Government or any agency thereof. 
INL/EXT-14-33070

Revision 0

\section{EISA 432 Energy Audits Best Practices: Software Tools}

November 2014

Idaho National Laboratory Idaho Falls, Idaho 83415

http://www.inl.gov

Prepared for the

U.S. Department of Energy

Office of Sustainability Performance

Under DOE Idaho Operations Office

Contract DE-AC07-05ID14517 



\section{SUMMARY}

Five whole building energy analysis software tools that can aid an energy manager with fulfilling energy audit and commissioning/retro-commissioning requirements were selected for review in this best practices study. A description of each software tool is provided as well as a discussion of the user interface and level of expertise required for each tool, a review of how to use the tool for analyzing energy conservation opportunities, the format and content of reports generated by the tool, and a discussion on the applicability of the tool for commissioning. For quick reference, a table is provided in Section 5 summarizing the capabilities of each the software tools.

\begin{tabular}{|c|c|c|c|c|c|}
\hline Software & EnergyIQ $^{\mathrm{TM}}$ & LEEP & FEDS & eQuest $^{\circledR}$ & simuwatt $^{\mathrm{TM}}$ \\
\hline $\begin{array}{l}\text { Software } \\
\text { developer }\end{array}$ & $\begin{array}{c}\text { Lawrence } \\
\text { Berkeley National } \\
\text { Lab }\end{array}$ & $\begin{array}{c}\text { Lawrence } \\
\text { Berkeley National } \\
\text { Lab }\end{array}$ & $\begin{array}{c}\text { Pacific } \\
\text { Northwest } \\
\text { National Lab }\end{array}$ & $\begin{array}{c}\text { James J Hirsch/ } \\
\text { Lawrence } \\
\text { Berkeley } \\
\text { National Lab } \\
\end{array}$ & $\begin{array}{l}\text { concept3D/ } \\
\text { National } \\
\text { Renewable } \\
\text { Energy Lab } \\
\end{array}$ \\
\hline Website & $\frac{\mathrm{http}: / / \text { energyiq.lbl. }}{\text { gov/ }}$ & http://leep.lbl.gov/ & $\frac{\text { http://www.pnl. }}{\text { gov/feds/ }}$ & $\frac{\text { http://www.doe } 2 .}{\text { com/equest/ }}$ & $\frac{\mathrm{http}: / / \text { simuwatt. }}{\mathrm{com} /}$ \\
\hline $\begin{array}{l}\text { Description } \\
\text { summary } \\
\text { from software } \\
\text { literature }\end{array}$ & $\begin{array}{l}\text { "Action-oriented" } \\
\text { benchmarking tool } \\
\text { for non-residential } \\
\text { buildings-- } \\
\text { bridges a gap by } \\
\text { providing a } \\
\text { standardized } \\
\text { opportunity } \\
\text { assessment based } \\
\text { on benchmarking } \\
\text { results, along with } \\
\text { decision-support } \\
\text { information to } \\
\text { help refine action } \\
\text { plans. }\end{array}$ & $\begin{array}{l}\text { Helps users to } \\
\text { quickly identify } \\
\text { and prioritize } \\
\text { potential energy } \\
\text { efficiency actions } \\
\text { in laboratory } \\
\text { facilities. It does } \\
\text { not require users } \\
\text { to have any } \\
\text { specialized } \\
\text { knowledge of } \\
\text { energy audits or } \\
\text { analysis. }\end{array}$ & $\begin{array}{l}\text { Windows-based } \\
\text { program } \\
\text { requires only } \\
\text { minimal user } \\
\text { experience and } \\
\text { input to perform } \\
\text { energy } \\
\text { efficiency } \\
\text { assessment } \\
\text { screenings as } \\
\text { well as detailed } \\
\text { energy retrofit } \\
\text { project analyses } \\
\text { across a wide } \\
\text { variety of } \\
\text { building types, } \\
\text { from single } \\
\text { buildings to } \\
\text { large } \\
\text { multi-building } \\
\text { campuses and } \\
\text { installations. }\end{array}$ & $\begin{array}{l}\text { A sophisticated, } \\
\text { yet easy to use } \\
\text { building energy } \\
\text { use analysis tool, } \\
\text { which provides } \\
\text { professional- } \\
\text { level results with } \\
\text { an affordable } \\
\text { level of effort. } \\
\text { This freeware } \\
\text { tool was } \\
\text { designed to allow } \\
\text { you to perform } \\
\text { building energy } \\
\text { use simulation. }\end{array}$ & $\begin{array}{l}\text { Replaces the } \\
\text { clipboard-and- } \\
\text { pencil approach } \\
\text { of most } \\
\text { building audits } \\
\text { with a package } \\
\text { that uses } \\
\text { sophisticated, } \\
\text { comprehensive } \\
\text { computer } \\
\text { modeling to } \\
\text { find more } \\
\text { potential } \\
\text { energy savings. } \\
\text { Tablet-based } \\
\text { front-end } \\
\text { working with } \\
\text { EnergyPlus } \\
\text { energy } \\
\text { simulation } \\
\text { modeling } \\
\text { software and } \\
\text { OpenStudio. }\end{array}$ \\
\hline
\end{tabular}




\section{ACKNOWLEDGEMENTS}

Thanks go to Christopher Ischay and Ernest Fossum of Idaho National Laboratory and Emily Stoddart of the U.S. Department of Energy Sustainability Performance Office for their review of this document and the valuable comments. Also to Matt Brown, Director of Sales Engineering at simuwatt for training using the simuwatt ${ }^{\mathrm{TM}}$ Energy Auditor software. 


\section{CONTENTS}

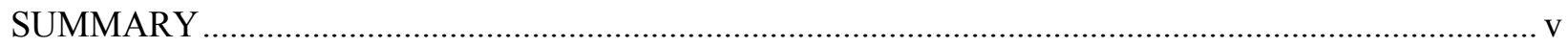

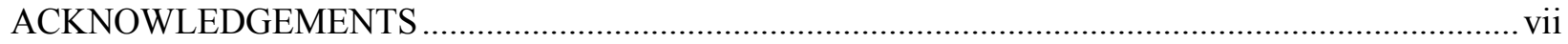

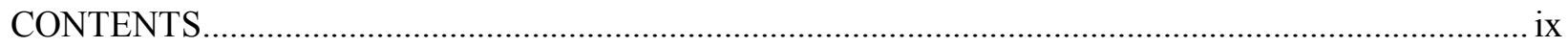

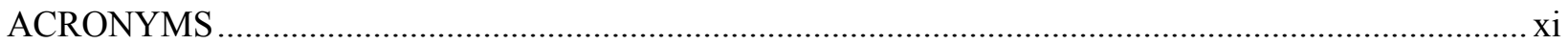

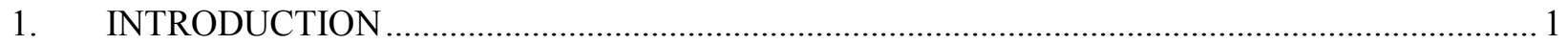

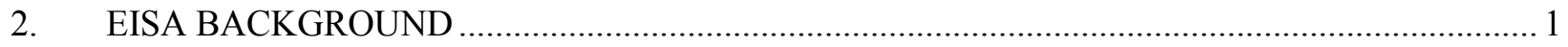

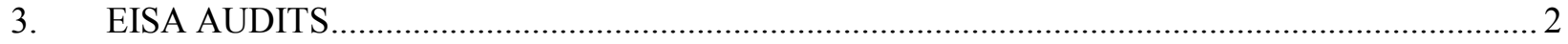

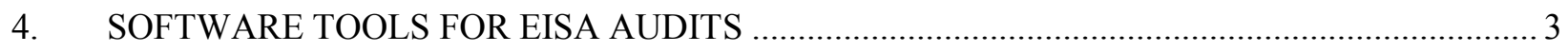

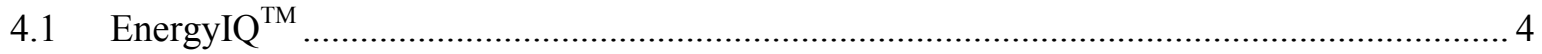

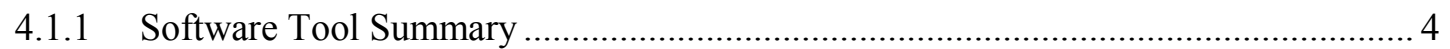

4.1.2 Using the Software Tool When Performing an Energy Audit ................................... 5

4.1.3 Analyzing Energy Conservation Measures ............................................................... 7

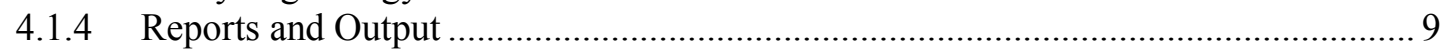

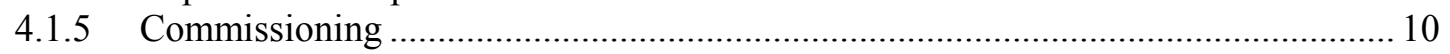

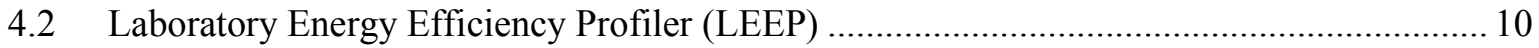

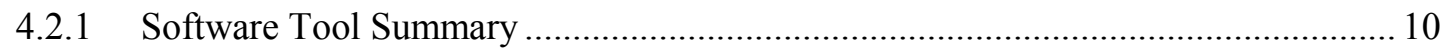

4.2.2 Using the Software Tool When Performing an Energy Audit ................................ 10

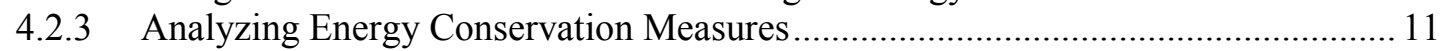

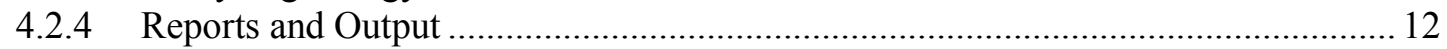

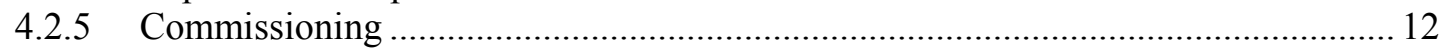

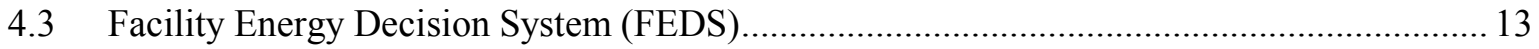

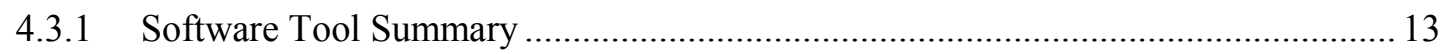

4.3.2 Using the Software Tool When Performing an Energy Audit ..................................... 14

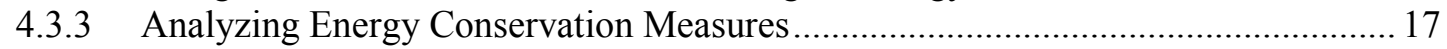

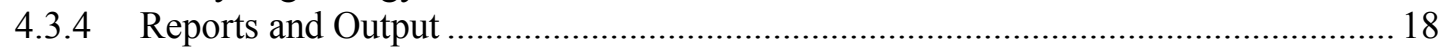

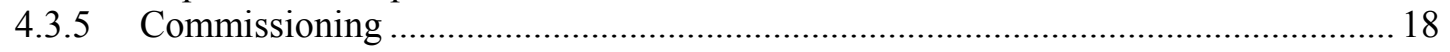

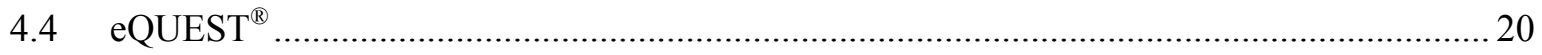

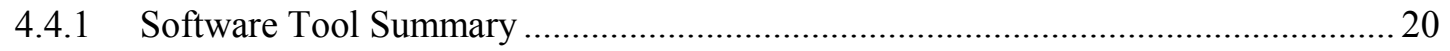

4.4.2 Using the Software Tool When Performing an Energy Audit .................................. 20

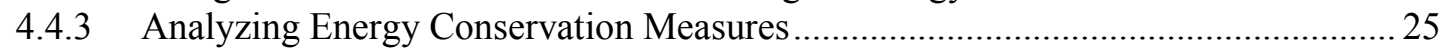

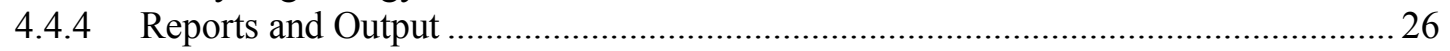

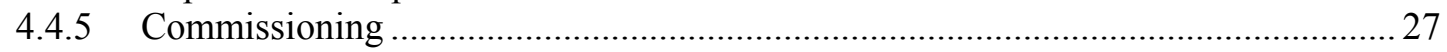

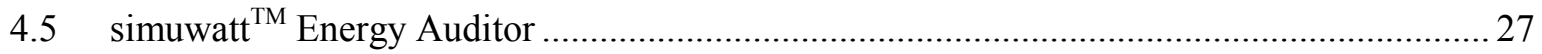

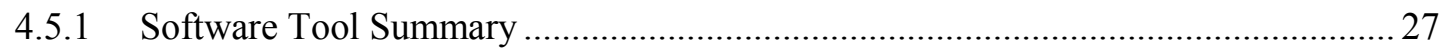

4.5.2 Using the Software Tool When Performing an Energy Audit ............................... 28

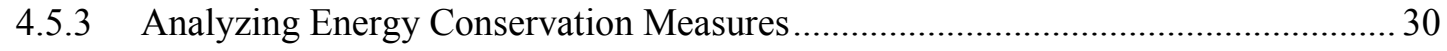

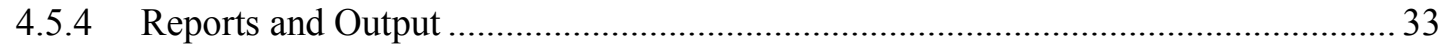

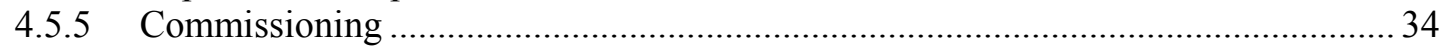




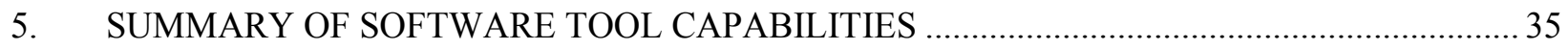

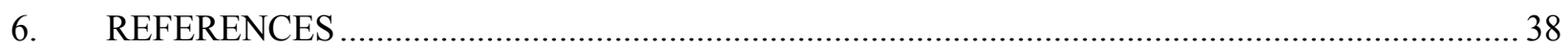

FIGURES

Figure 1. EnergyIQ - "My Buildings” (http://energyiq.lbl.gov/). ........................................................ 5

Figure 2. EnergyIQ - Building Features (http://energyiq.lbl.gov/). ..................................................... 6

Figure 3. EnergyIQ - Energy Conservation Opportunity List (http://energyiq.lbl.gov/)........................... 7

Figure 4. EnergyIQ - Using the CEUS Database to Gauge Potential Savings

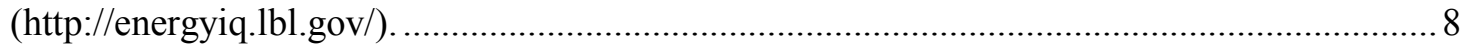

Figure 5. EnergyIQ - Energy Savings Potential by Fuel Type (http://energyiq.lbl.gov/). ......................... 9

Figure 6. LEEP - Input Facility Data (http://leep.lbl.gov/). …............................................................. 11

Figure 7. LEEP - Review Actions Report (http://leep.lbl.gov/)......................................................... 12

Figure 8. FEDS - Minimum Information (http://www.pnl.gov/feds/).................................................. 15

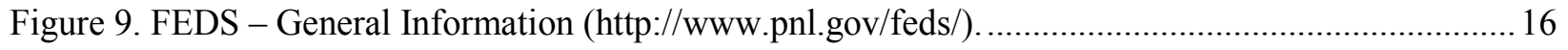

Figure 10. FEDS - Lighting Technology Inputs (http://www.pnl.gov/feds/)........................................ 17

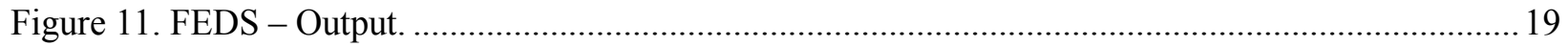

Figure 12. eQUEST - Design Wizard Menu (http://www.doe2.com/equest/)....................................2 21

Figure 13. eQUEST - Using a Design Wizard (http://www.doe2.com/equest/). ...................................22

Figure 14. eQUEST - Building Model 3-D View (http://www.doe2.com/equest/)................................23

Figure 15. eQUEST - HVAC Systems (http://www.doe2.com/equest/)...............................................24

Figure 16. eQUEST - Model Data Table (http://www.doe2.com/equest/)............................................25

Figure 17. eQUEST - Energy Efficiency Measure Wizard (http://www.doe2.com/equest/)...................26

Figure 18. eQUEST - Single-Run Reports and Output (http://www.doe2.com/equest/).......................27

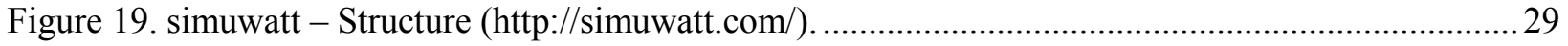

Figure 20. simuwatt - Using the Building Component Library (Photo credit: Dennis Schroeder http://www.nrel.gov/news/features/feature_detail.cfm/feature_id=4300).............................. 30

Figure 21. simuwatt model in OpenStudio - Space Types (https://www.openstudio.net/)......................31

Figure 22. simuwatt model in OpenStudio - Parametric Analysis Tool - Measure Library (https://www.openstudio.net/).

Figure 23. simuwatt model in OpenStudio - Parametric Analysis Tool Results

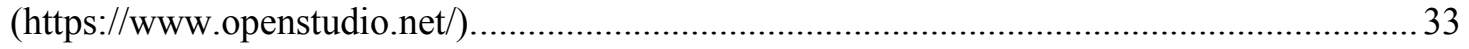

Figure 24. simuwatt model in OpenStudio - Results (https://www.openstudio.net/)............................. 34 


\section{ACRONYMS}

ASHRAE American Society of Heating, Refrigerating and Air-Conditioning Engineers

BAS Building automation system

BCL Building Component Library

BTU British thermal unit

CBECS Commercial Buildings Energy Consumption Survey

CD Compact disk

CEUS California Commercial End-Use Survey

DOE U.S. Department of Energy

ECM Energy conservation measure

ECO Energy conservation opportunity

EIA U.S. Energy Information Administration

EISA Energy Independence and Security Act of 2007

EPA Environmental Protection Agency

ESCO Energy service company

FEDS Facility Energy Decision System

FEMP Federal Energy Management Program

HVAC Heating, ventilation, and air-conditioning

INL Idaho National Laboratory

kWh kilowatt-hour

LBNL Lawrence Berkeley National Laboratory

LEEP Laboratory Energy Efficiency Profiler

NREL National Renewable Energy Laboratory

PC personal computer

PDF Adobe portable document format

PNNL Pacific Northwest National Laboratory

$\mathrm{RCx} \quad$ retro-commissioning

ROI return on investment

Sq. ft. square feet

W Watt

WBDG Whole Building Design Guide 


\section{EISA 432 Energy Audits Best Practices: Software Tools}

\section{INTRODUCTION}

Software tools can aid the energy auditing process through the means of providing a standardized analysis method and a data collection structure. The U.S. Department of Energy (DOE) Sustainability Performance Office funded Idaho National Laboratory (INL) to analyze several energy modeling software packages. This analysis will provide federal agencies with an overview of software tools available to assist energy managers in completing energy audits and commissioning of their responsible federal facilities under Section 432 of the Energy Independence and Security Act of 2007 (EISA).

The DOE Office of Energy Efficiency and Renewable Energy web page, "Building Energy Software Tools Directory," provides a comprehensive listing of software to analyze whole building energy use. The full listing of software can be reviewed via the following link:

http://apps1.eere.energy.gov/buildings/tools_directory/subjects_sub.cfm

Five whole building analysis software tools from this listing, of varying capability and format, were selected for review in this best practices study. Each of the reviewed software tools, or components of the calculation engines, was developed by or in collaboration with DOE national laboratories. While only a handful of software tools could be reviewed, an attempt was made to select an array of tools representative of various platforms and capabilities. The intent of this report is to provide an overview of the use, level of effort, and functionality of a few software tools, and allow the energy manager to decide whether a tool will suit their specific needs and requirements.

\section{EISA BACKGROUND}

The opening paragraph of the Energy Independence and Security Act of 2007 states:

"To move the United States toward greater energy independence and security, to increase the production of clean renewable fuels, to protect consumers, to increase the efficiency of products, buildings, and vehicles, to promote research on and deploy greenhouse gas capture and storage options, and to improve the energy performance of the Federal Government, and for other purposes. " (Energy Independence and Security Act of 2007)

Section 432 of the statue states:

"beginning on the date that is 180 days after the date of enactment of this subsection and annually thereafter, energy managers shall complete, for each calendar year, a comprehensive energy and water evaluation for approximately 25 percent of the facilities of each agency that meet the criteria under paragraph (2)(B) in a manner that ensures that an evaluation of each such facility is completed at least once every 4 years. " (Energy Independence and Security Act of 2007) 


\section{EISA AUDITS}

The document "Facility Energy Management Guidelines and Criteria for Energy and Water Evaluations in Covered Facilities (42 U.S.C. 8253 Subsection (f), Use of Energy and Water Efficiency Measures in Federal Buildings)" provides the following definition and clarifications regarding energy and water evaluations and will be referred to as "EISA Guidelines" throughout this report.

\section{"IV. Energy and Water Evaluations}

\section{A. Definitions and Clarifications}

Paragraph (3) of subsection (f) of the statute (42 U.S.C. 8253(f)(3)) states that “...energy managers shall complete, for each calendar year, a comprehensive energy and water evaluation for approximately 25 percent of the [covered] facilities of each agency...in a manner that ensures that an evaluation of each such facility is completed at least once every 4 years." (42U.S.C. 8253(f)(3)(A)) Further, "[a]s part of the evaluation ..., the energy manager shall identify and assess recommissioning measures (or, if the facility has never been commissioned, retrocommissioning measures) for each such facility."

To assist energy managers in gaining the needed expertise for carrying out energy and water assessments and commissioning, the U.S. Department of Energy's Federal Energy Management Program (FEMP) and the National Institute of Building Sciences "Whole Building Design Guide" (WBDG) offer online training courses. Courses can be found on the WBDG website:

\section{http://www.wbdg.org/education/femp_e.php}

- Recommended courses:

- FEMP02, "Planning an Energy Assessment for Federal Facilities"

- FEMP01, "Commissioning for Existing Federal Buildings"

- FEMP06, "Managing Water Assessment in Federal Facilities."

The Pacific Northwest National Laboratory (PNNL) provides "A Guide to Energy Audits" document to assist energy managers with planning and carrying out energy audits. Energy audits can vary in the level of detail depending on the scope of the audit. The PNNL report provides a breakdown of the common scopes based on the energy audit format of the American Society of Heating, Refrigerating and Air-Conditioning Engineers (ASHRAE).

"Level I: Site Assessment or Preliminary Audits identify no-cost and low-cost energy saving opportunities, and a general view of potential capital improvements. Activities include an assessment of energy bills and a brief site inspection of your building.

Level II: Energy Survey and Engineering Analysis Audits identify no-cost and low-cost opportunities, and also provide EEM recommendations in line with your financial plans and potential capital-intensive energy savings opportunities. Level II audits include an in-depth analysis of energy costs, energy usage and building characteristics and a more refined survey of how energy is used in your building.

Level III: Detailed Analysis of Capital-Intensive Modification Audits (sometimes referred to as an "investment grade" audit) provide solid recommendations and financial analysis for major capital investments. In addition to Level I and Level II activities, Level III audits include monitoring, data collection and engineering analysis.” (Michael Baechler \& Cindy Strecker, 2011) 


\section{SOFTWARE TOOLS FOR EISA AUDITS}

No energy audit is complete without first analyzing the building energy consumption through benchmarking. ENERGY STAR ${ }^{\circledR}$ Portfolio Manager ${ }^{\circledR}$ has been designated the benchmarking tool for federal agencies (Presidential Memorandum -- Federal Leadership on Energy Management, 2013). Benchmarking allows the energy manager to understand how a building compares with other similar buildings and can identify buildings with high energy consumption per square foot. Once benchmarking has been completed then the energy manager can prioritize the building stock for energy audits.

A variety of software tools exists to assist with identifying and quantifying energy saving opportunities though an energy audit. All software tools require the assistance of knowledgeable facility operating staff who can provide information regarding building operating hours and installed system configurations. The software tools discussed in this report range from web-based tools that provide a high level, or first look, at possible energy conservation opportunities to hourly energy simulation models which provide detailed and highly accurate energy savings calculations.

For this report, software tools are divided into two groups: opportunity identifiers and energy simulation.

Opportunity identifiers are tools requiring a minimal amount of data, user time, and specialized user expertise, which will provide suggestions of energy conservation opportunities. These tools generate a listing of possible energy conservation opportunities from databases and are focused on technology solutions that are more energy efficient than equipment currently installed in the building. However, due to the focus on technology, these tools are not able to identify many operational and maintenance changes that could reduce energy consumption. Primarily applicable for preliminary and ASHRAE Level I audits and some tools may be used for Level I/II audits. (Software tools reviewed: EnergyIQ, LEEP, FEDS.)

Sophisticated building energy simulation engines - such as DOE-2 and EnergyPlus - provide highly accurate energy calculations but require a high level of user expertise and building information. Energy simulation tools have the ability and flexibility required for calculating the energy savings of energy conservation measures identified through an energy audit and/or the commissioning process. These tools are suited for energy auditors with experience that will enable them to assess the current building equipment and operation, and develop a custom list of energy conservation opportunities. Applicable for ASHRAE Level II and Level III audits. (Software tools reviewed: FEDS, eQUEST [DOE-2], simuwatt [EnergyPlus]).

The software tool FEDS falls into both categories as it has opportunity identification and energy simulation capabilities.

The evaluation format for the software review sections is as follows:

\section{Software Tool Summary}

- Description

- Software developer

- Cost

- Applicable use:

- Preliminary Audit, Level I Audit, Level II Audit, Level III Audit

Using the Software as a Tool When Performing an Energy Audit

- User interface

- Data input required

- Alignment and synergies with ENERGY STAR Portfolio Manager 
- Time commitment

- Level of expertise required

\section{Analyzing Energy Conservation Measures}

- Developing energy conservation measures

- Level of expertise required

\section{Reports and Output}

- Report format

- Output and report information generated

- Level of detail

- Life-cycle cost information

\section{Commissioning}

- Applicability of software tool for commissioning and/or retro-commissioning ( $\mathrm{RCx}$ ).

This report will refer to energy conservation measures (ECM) and energy conservation opportunities (ECO) with the distinguishing difference being that an ECO is an identified possible energy saving idea that needs further development while an ECM is a more defined energy saving technology or action. For example, an ECO would be "reduce lighting load by 10\%" and an ECM would be "replace (50) 100 Watt incandescent lamps with (50) 26 Watt compact fluorescent lamps."

\subsection{EnergylQ ${ }^{\mathrm{TM}}$}

\subsubsection{Software Tool Summary}

The web-based tool EnergyIQ ${ }^{\mathrm{TM}}$ was developed by Lawrence Berkeley National Laboratory. EnergyIQ relies on benchmarking data from the California Commercial End-Use Survey (CEUS) and Commercial Buildings Energy Consumption Survey (CBECS) from the U.S. Energy Information Administration (EIA).

"EnergyIQ - the first "action-oriented" benchmarking tool for non-residential buildings... providing a standardized opportunity assessment based on benchmarking results, along with decision-support information to help refine action plans.

Action-oriented benchmarking is particularly useful for opportunity-assessment purposes, improving on simplified benchmarking processes and helping lay the groundwork for investment-grade audits and professional engineering calculations.

Based on user inputs, the tool generates a list of opportunities and recommended actions. Users can then explore the "Decision Support" module for helpful information on how to refine action plans, create design-intent documentation, and implement improvements. This includes information on best practices, links to other energy analysis tools, and more." (About: EnergyIQ) 
The tool is free and requires the user to create an account on the website in order to enter building information and view recommended actions. EnergyIQ provides high level recommendations and is applicable for preliminary and "desk-top" audits. Energy conservation opportunities tend to be technology based due to the database nature of the tool. This tool is not able to identify operating performance improvements that would be found by performing retro-commissioning.

Website: $\quad$ http://energyiq.lbl.gov/EnergyIQ/index.jsp

Cost: $\quad$ Free

Energy Audit Type: Preliminary/Level I

\subsubsection{Using the Software Tool When Performing an Energy Audit}

The EnergyIQ web-based tool requires basic building information and can be used to analyze a building in about an hour. Users should have a general knowledge of building systems and specific knowledge of the lighting, HVAC, building construction materials, and operating hours for the building being analyzed.

Users register on the website and create a login ID and password in order to create an account and access the full features of the website. The tool includes several sample buildings that demonstrate the features and capabilities of the online software tool. Users can walk through the sample building sets to familiarize themselves with the tool prior to adding their own building data.

Information about a building is entered into the "My Buildings" tab (see Figure 1). Click on the "Add Your Building" button to begin the process. Alternatively, EnergyIQ allows the user to connect to Portfolio Manager to import buildings and data the user has previous set up in Portfolio Manager.

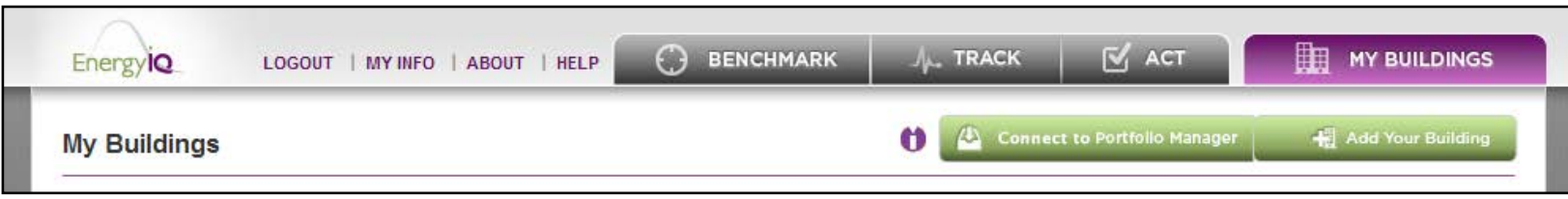

Figure 1. EnergyIQ - "My Buildings” (http://energyiq.lbl.gov/).

The tool walks the user through five steps in setting up the building: building details, peer group, features, energy use, and targets. Basic information required by the tool includes building square feet, number of employees, building construction year, and annual energy consumption for each fuel type. In the "Building Details" section the user enters the building name, address, city and state, building square footage, and number of occupants.

EnergyIQ has two peer group options to use for benchmarking: CEUS or CBECS databases. Once the peer group database is defined, parameters are then selected to further refine the peer group, such as: floor area, climate, building type, vintage, and location.

Step three is to add the "Features" of the building, which are the energy using components and equipment in the building, such as: indoor and outdoor lighting, air handlers, chillers and supporting equipment, heating equipment, domestic hot water, refrigeration, and building envelope (see Figure 2). The tool includes pull-down menus that allow the user to select building equipment from a prepopulated list of equipment typical for buildings. The user also enters detailed information such as operating hours and equipment efficiency ratings. Users may enter as much or as little information as they wish; however, the tool relies on the information entered into the "Features" section to identify energy conservation opportunities (ECO). Thus, the more information and details the user provides the more energy saving options the tool will be able to evaluate. 


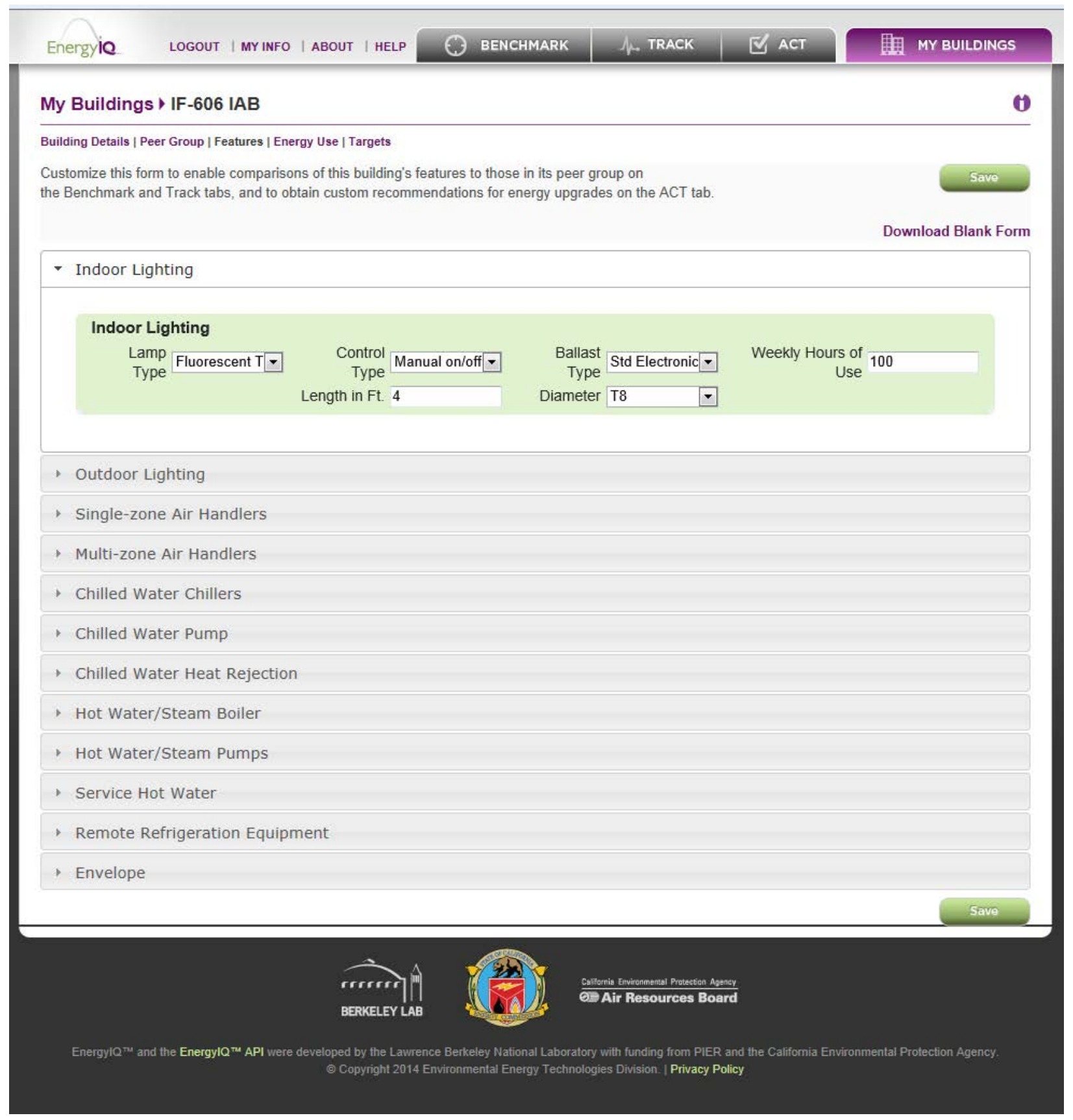

Figure 2. EnergyIQ - Building Features (http://energyiq.lbl.gov/).

The next step is to add the annual energy consumption and cost data for the building. Energy consumption is entered for each fuel type (electricity, natural gas, renewables, fuel oil, district steam, district chilled water, etc.). Multiple years of data may be added that will allow the user to track the historic energy performance and cost trends.

Once the building profile has been created, three steps are available for evaluating the building in EnergyIQ: Benchmark, Track, and Act. "Benchmark" provides a ranking against the selected peer group database; "Track" displays the historic energy consumption metrics; and the third option, "Act" offers a listing of energy conservation opportunities that may be applicable to the building. 


\subsubsection{Analyzing Energy Conservation Measures}

The "Act" tab of the tool provides a listing of possible energy conservation opportunities based on the building "Features" entered by the user. The tool automatically generates a list of possible ECOs from a library of 50 possible upgrades, many with three efficiency levels, which could be applicable to the building (see Figure 3). The list is high level and each ECO item includes a pie chart to represent the possible return on investment (ROI) potential.

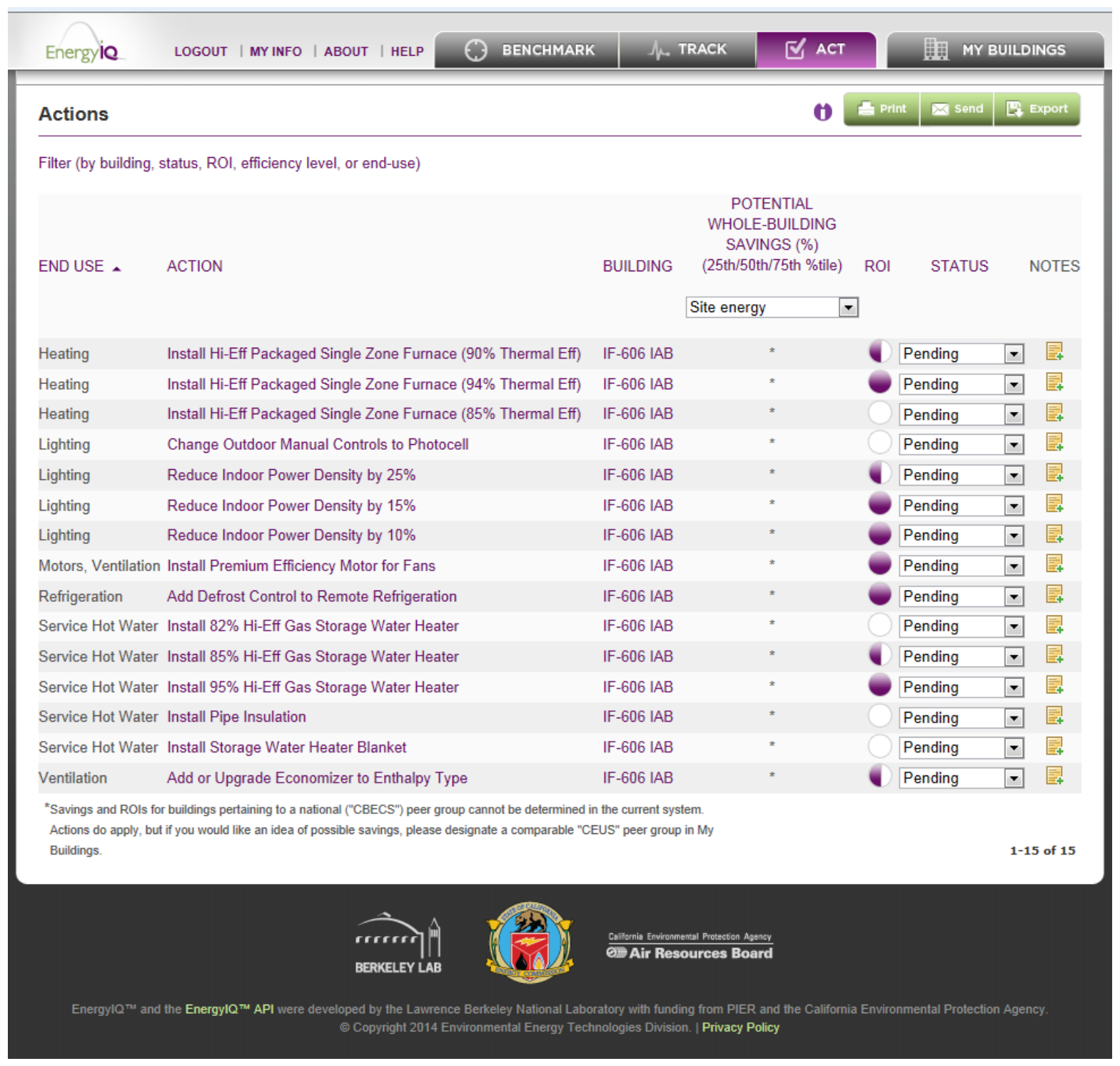

Figure 3. EnergyIQ - Energy Conservation Opportunity List (http://energyiq.lbl.gov/).

"Potential Whole-Building Savings" is expressed as a percent of the total building energy use. Representative savings ranges are given for buildings at three different percentiles -25 th, 50 th, and 75th - where the higher percentile represents higher energy consumption compared with the benchmark group. Savings can be displayed for total site energy, total source energy, electricity only, fuel only, total cost, peak electric demand, and emissions. For EnergyIQ to provide "Potential Whole-Building Savings" metrics, the building must be benchmarked against the CEUS peer group (see Figure 4). This can easily be changed through the "My Buildings" tab by selecting the California Buildings (CEUS) as the Peer Group Data Set. 


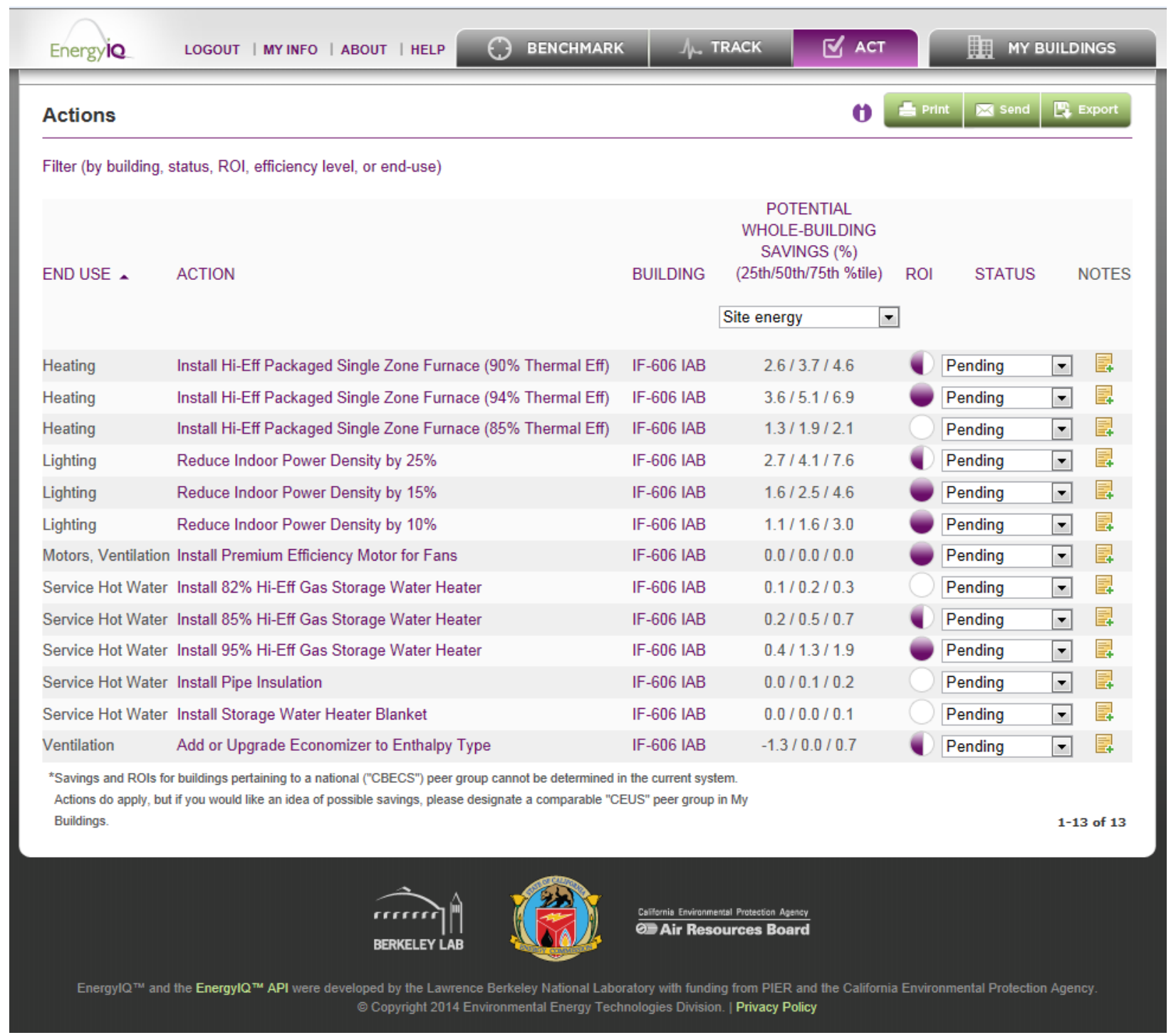

Figure 4. EnergyIQ - Using the CEUS Database to Gauge Potential Savings (http://energyiq.lbl.gov/).

The energy savings potential includes interactive effects within the savings, for example, a lighting ECO will include the heating and cooling energy impacts along with the lighting energy savings. Figure 5 shows the potential savings for building fuel use. Notice the lighting ECOs show an increase in fuel use (negative savings) due to the reduced heat to the space that occurs when more energy efficient lighting options are deployed. 


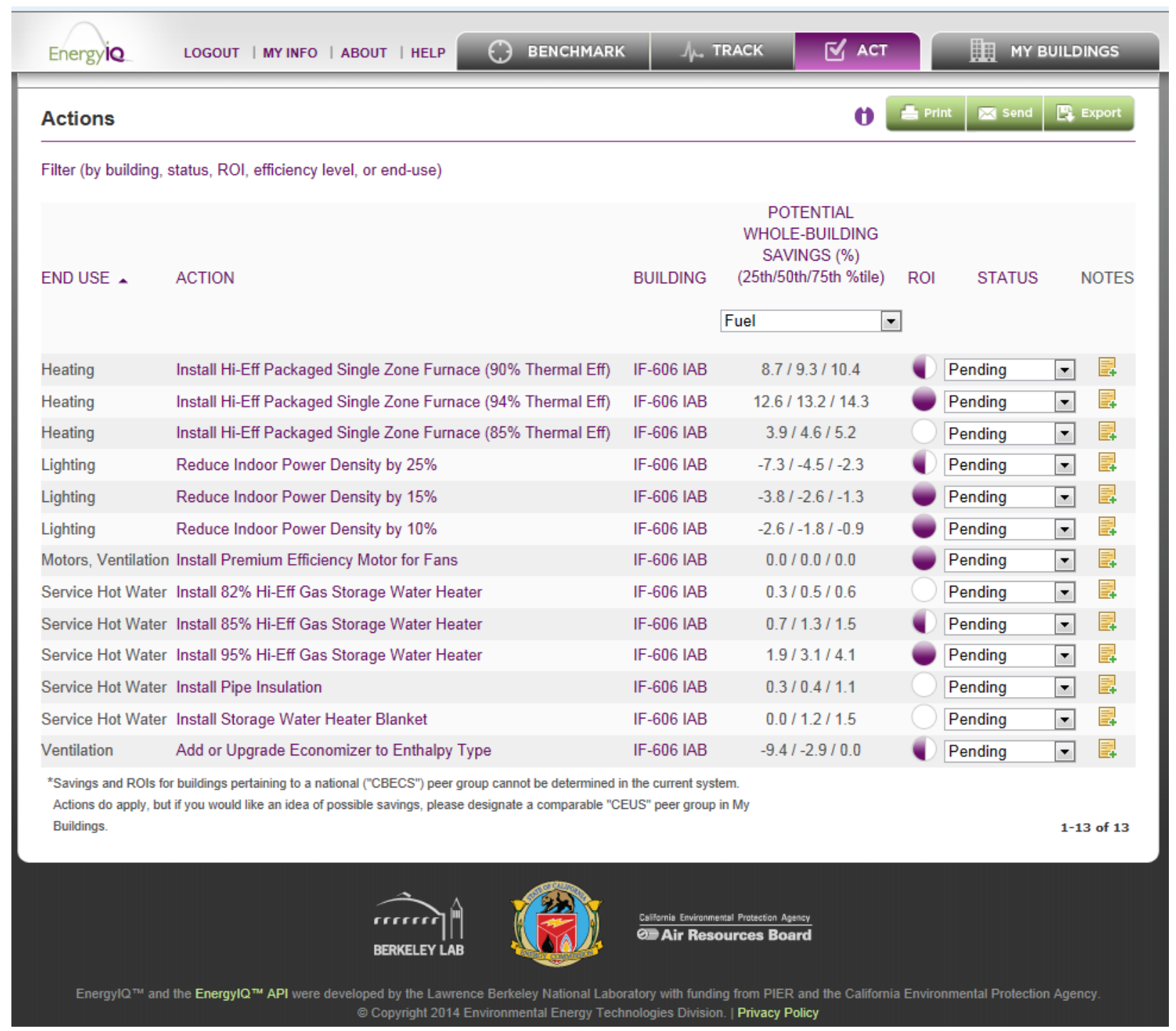

Figure 5. EnergyIQ - Energy Savings Potential by Fuel Type (http://energyiq.lbl.gov/).

The user can assess the output from the tool to determine opportunities that best meet their energy savings objectives and further investigate each opportunity with a more detailed analysis.

\subsubsection{Reports and Output}

The tool generates an online report listing of potential ECOs. The report can also be exported to PDF or spreadsheet format. Users may enter notes for any of the ECOs to elaborate on the measure or add further details to the report output.

In the case where an energy manager is seeking a high level, first cut of possible energy conservation projects, EnergyIQ, is a useful tool that is quickly and easily employed. Actions identified by the tool serve as a starting point for further investigation to determine energy savings and cost effective projects. Equipment vendors, consultants, or an ESCO may be a resource to more fully develop the energy saving opportunities from the suggested actions into energy conservation measures (ECM) including the implementation cost, energy savings, and return on investment details required for the EISA audit report. 


\subsubsection{Commissioning}

The EnergyIQ tool was not designed with the sufficient sophistication and analysis capability to allow it to be utilized as an energy savings calculation tool in conjunction with the commissioning process.

\subsection{Laboratory Energy Efficiency Profiler (LEEP)}

\subsubsection{Software Tool Summary}

"Laboratory Energy Efficiency Profiler (LEEP) helps users to quickly identify and prioritize potential energy efficiency actions in laboratory facilities. It does not require users to have any specialized knowledge of energy audits or analysis. The tool inputs are the key characteristics of the facility's ventilation, heating, cooling and lighting systems as well as plug and process equipment. Based on these inputs, the tool provides information on the relevance, impact, and comparative cost of over 60 actions to reduce energy use. These results can then be used to help establish the scope and priorities for more detailed energy audits." (LEEP Home page)

LEEP was developed by Lawrence Berkeley National Laboratory for the Laboratories for the 21st Century ${ }^{\circledR}\left(\right.$ Labs $\left.21^{\circledR}\right)$ program - a joint federal program sponsored by the U.S. Department of Energy's Federal Energy Management Program (FEMP) and the U.S. Environmental Protection Agency (EPA).
Website:
http://leep.lbl.gov/
Cost:
Free
Energy Audit Type: Preliminary/Level I

\subsubsection{Using the Software Tool When Performing an Energy Audit}

LEEP is a web-based tool that allows users to enter basic information on laboratory use and equipment. Users simply need to register on the website and create a login ID and password to use LEEP. For a user who is familiar with the lab building, such as the building operator or laboratory manager, the analysis can be completed in about 1 hour. Users should have a general knowledge of laboratory building systems and specific knowledge of the lighting, HVAC, laboratory equipment, and operating parameters of the lab equipment.

Prior to using LEEP it is recommended to benchmark the laboratory facility with Portfolio Manager and the Labs21 Energy Benchmarking Tool. Benchmarking helps to provide the user with a sense of how the energy consumption of their lab stacks up against laboratories from around the country.

The LEEP web-based tool walks users through four steps to complete the laboratory assessment. The first step - the tab labeled "Select Facility" - is to add the facility to the tool, or select a previously created laboratory building for which additional information will be added. Next, "Select Assessment Scope," the user selects the systems they wish to evaluate with the tool: ventilation, heating and cooling, process loads, and lighting. The user can select all of the systems or as few as one category. During the third step, "Input Facility Data," the user begins by entering general information about the building such as location, building square footage, climate zone, and laboratory type. LEEP automatically sets up one tab for each of the categories selected by the user in the "Select Assessment Scope" step (see Figure 6). Users go through each of the tabs and enter the building equipment and operating information using pull-down menus and text boxes.

- Ventilation - supply system, lab system, exhaust system, and control system

- Heating and Cooling - heating system, cooling system, and control system 
- Process and Plug Loads

- $\quad$ Lighting.

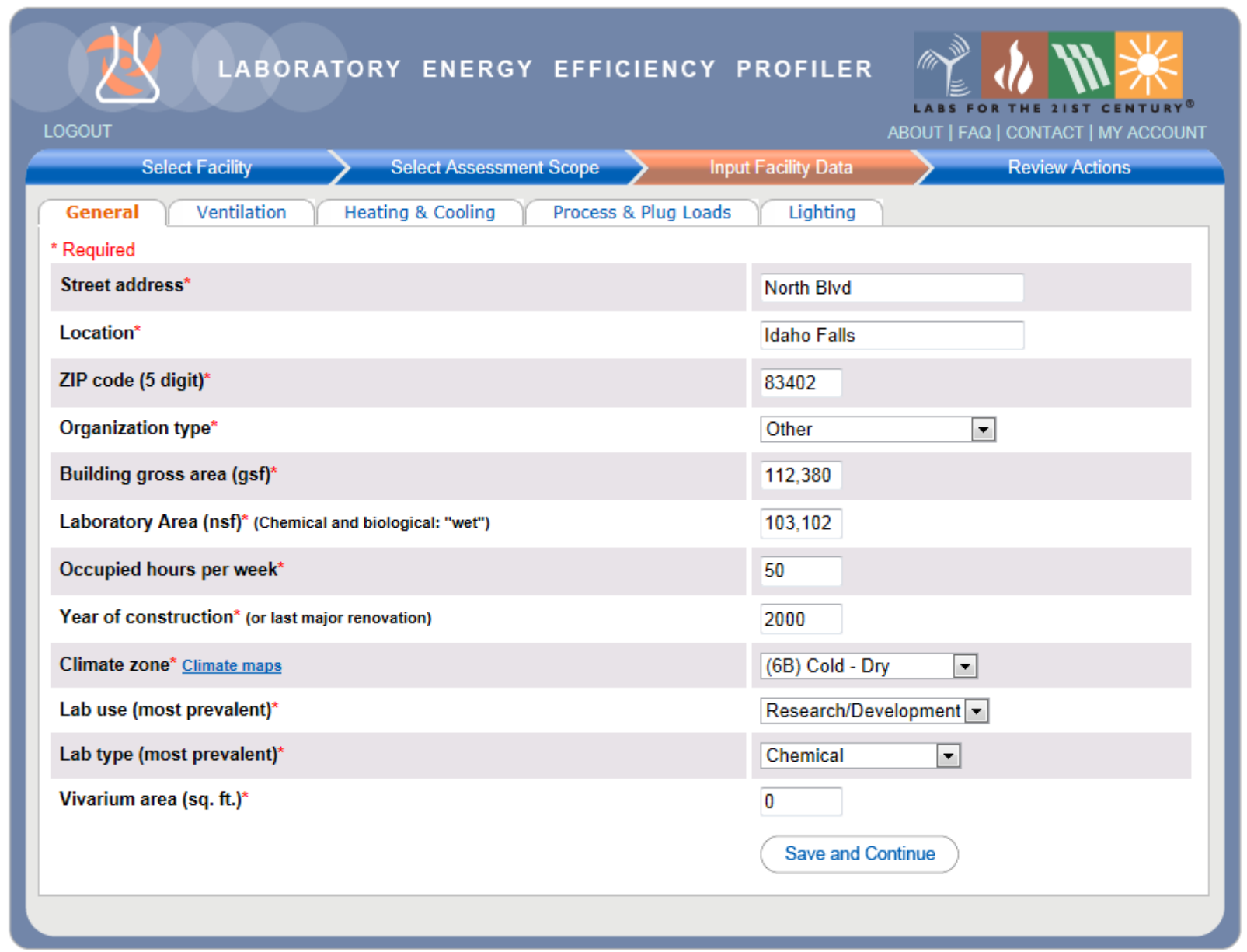

Labs21 : Berkeley Lab :: Disclaimer :: Web Master

Figure 6. LEEP - Input Facility Data (http://leep.lbl.gov/).

LEEP stores and saves the data entered into the tool so users may add information over multiple sessions. The last step is "Review Actions" where LEEP generates a listing of possible energy conservation opportunities based on the provided input. Should the user provide additional lab information in the "Input Facility Data" section, the list of energy conservation opportunities will be updated to reflect the input.

\subsubsection{Analyzing Energy Conservation Measures}

From the listing of actions LEEP provides in the "Review Actions" section (see Figure 7), the user is quickly able to assess actions based on relevance, impact, and cost. As LEEP is an opportunity identifier tool, the items listed in the "Review Actions" section provide a preliminary list of items for further investigation. 


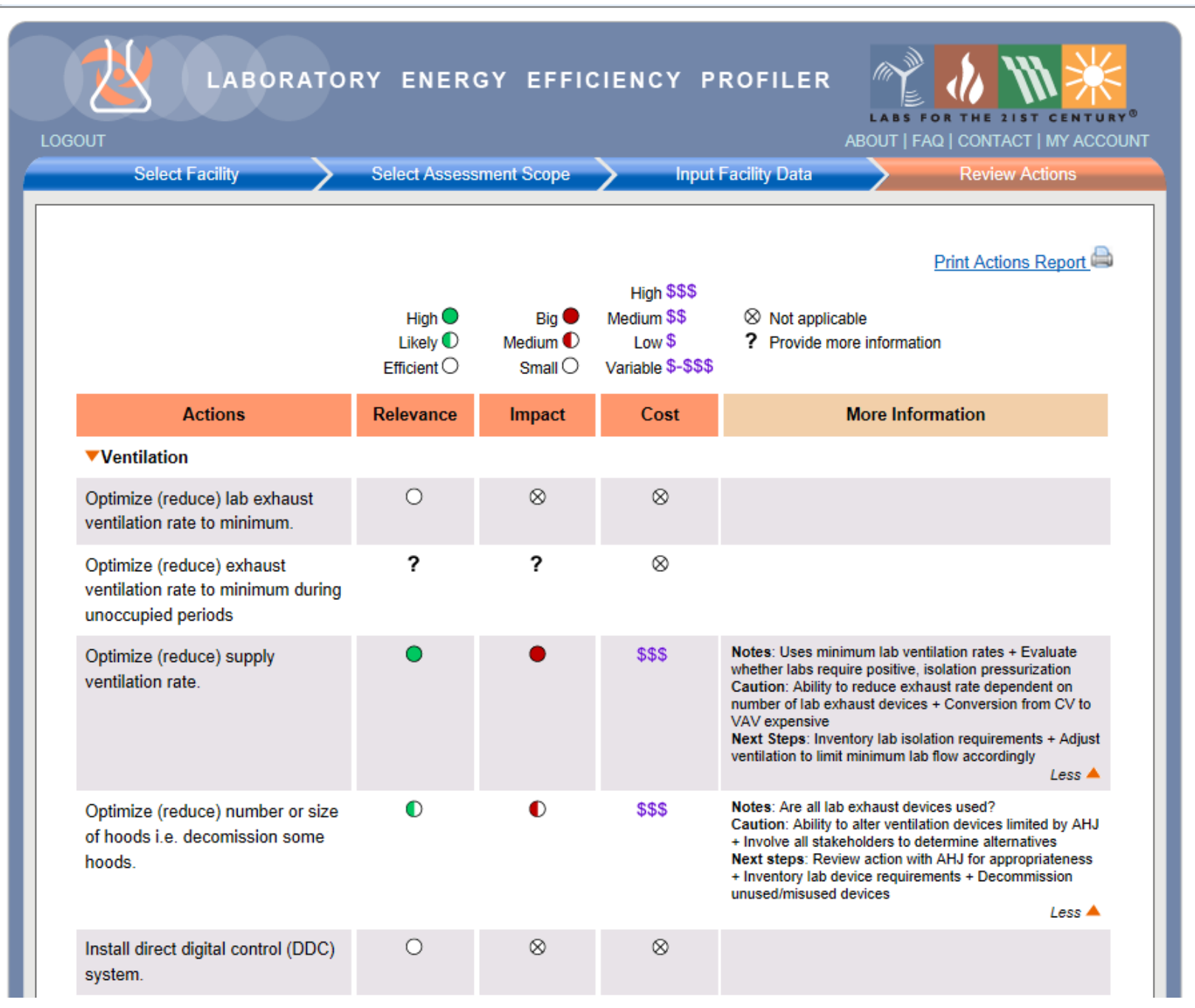

Figure 7. LEEP - Review Actions Report (http://leep.lbl.gov/).

LEEP, similar to EnergyIQ, is useful where an energy manager is seeking a high level, first cut of possible energy conservation projects.

\subsubsection{Reports and Output}

The tool generates an online report listing of potential ECOs, which can be printed or viewed on the computer screen. The user can assess the output from the tool to determine opportunities that best meet their energy savings objectives and further investigate those opportunities with a more detailed analysis. Equipment vendors, consultants, or an ESCO may be a resource to more fully develop the energy saving opportunities from the suggested actions listing into energy conservation measures (ECM), which includes the implementation cost, energy savings, and return on investment details required for the EISA audit report.

\subsubsection{Commissioning}

The LEEP tool was not designed with sufficient sophistication and analysis capability to allow it to be utilized as an energy savings calculation tool in conjunction with the commissioning process. 


\subsection{Facility Energy Decision System (FEDS)}

\subsubsection{Software Tool Summary}

Facility Energy Decision System (FEDS) software is a desktop computer tool developed by Pacific Northwest National Laboratory.

"FEDS is a user-friendly, Windows-based, menu-driven software program for assessing the energy efficiency resource potential of facilities ranging from single buildings to multi-building campuses and large Federal installations. In the first pass, a user typically enters only high-level installation information (number, age, size, and types of buildings and energy systems). The internal database of typical energy-system configurations and performance data then infers likely building parameters, and the sophisticated energy simulation and optimization models estimate the net present value of potential energy retrofits.

Using FEDS with only the minimum set input provides utility, institution, agency, energy, or installation managers with a simple 3-4 hour method to:

- estimate resource efficiency potential at a single multi-building installation with limited metered energy-use data

- characterize and prioritize the most promising building and end-use retrofit project opportunities

- estimate capital investment requirements and potential energy and cost savings based upon Federal life-cycle cost economics." (Facility Energy Decision System User's Guide Release 6.0)

FEDS recommends a six-step process for evaluating energy conservation opportunities:

1. Start with basic information

2. Choose the building sets with the most promise

3. Gather additional data on most promising building sets

4. Enter additional data

5. Calibrate model (adjust loads, operating hours) to best fit actual building energy consumption

6. Run optimization.

Output files are plain text and comma-separated variable formats that can be opened with document and spreadsheet programs.

FEDS is also capable of evaluating groups of similar buildings as a "set" rather than separately evaluating each individual building. For example, many similar housing units on a military base may be grouped and evaluated together as a set. The following list is of building types that can be analyzed using FEDS. Most of the building types supported by FEDS also have a corresponding property type in Portfolio Manager. 
Civilian Building Types:
Assembly
Education
Food Sales
Food Service
Health Care
Lodging
Mercantile and Service
Office

Military Building Types:

Administration
Barracks
Chapel
Clinic
Clubs
Commissaries
Dining Halls
Electronics
Exchange Facilities
Single Family Detached House
Single Family Attached House
Duplex
Multi-Family 3 or More Unit
Mobile Homes
Guest Houses
Energy conservation opportunities are technology
is not able to identify operating performance improver
tro-commissioning. However, since the user is able to
Ensible to calculate savings for many operation and m
Eersion:
Website:
Cost:
commissioning process.

\author{
Public Order/Safety \\ Warehouse and Storage \\ Other \\ Single Family Detached \\ Single Family Attached \\ 2 to 4 Unit Multifamily \\ 5 or More Unit Multifamily \\ Mobile Homes
}

\author{
Hangar \\ Hospital \\ Labs \\ Laundry \\ Morale, Welfare, and Recreation \\ Military Other \\ Recreation \\ Schools and/or Training \\ Security \\ Shops \\ Storage \\ Warehouse \\ Commissary - Sales \\ Commissary - Warehouse
}

Energy conservation opportunities are technology based due to the database nature of the tool. This tool is not able to identify operating performance improvements that would be found by performing retro-commissioning. However, since the user is able to select schedules and equipment parameters it is possible to calculate savings for many operation and maintenance opportunities identified through the

\subsubsection{Using the Software Tool When Performing an Energy Audit}

The FEDS software CD contains the program, sample output files, and a series of data collection forms to aid the user in gathering and organizing building equipment and operating information during an audit walk through. FEDS recommends users begin by entering basic "Minimum Set" information and the 1-page data collection form can be used to assist with gathering this data (see Figure 8). A helpful and detailed Users Guide in PDF format is provided to walk users through creating a model. 


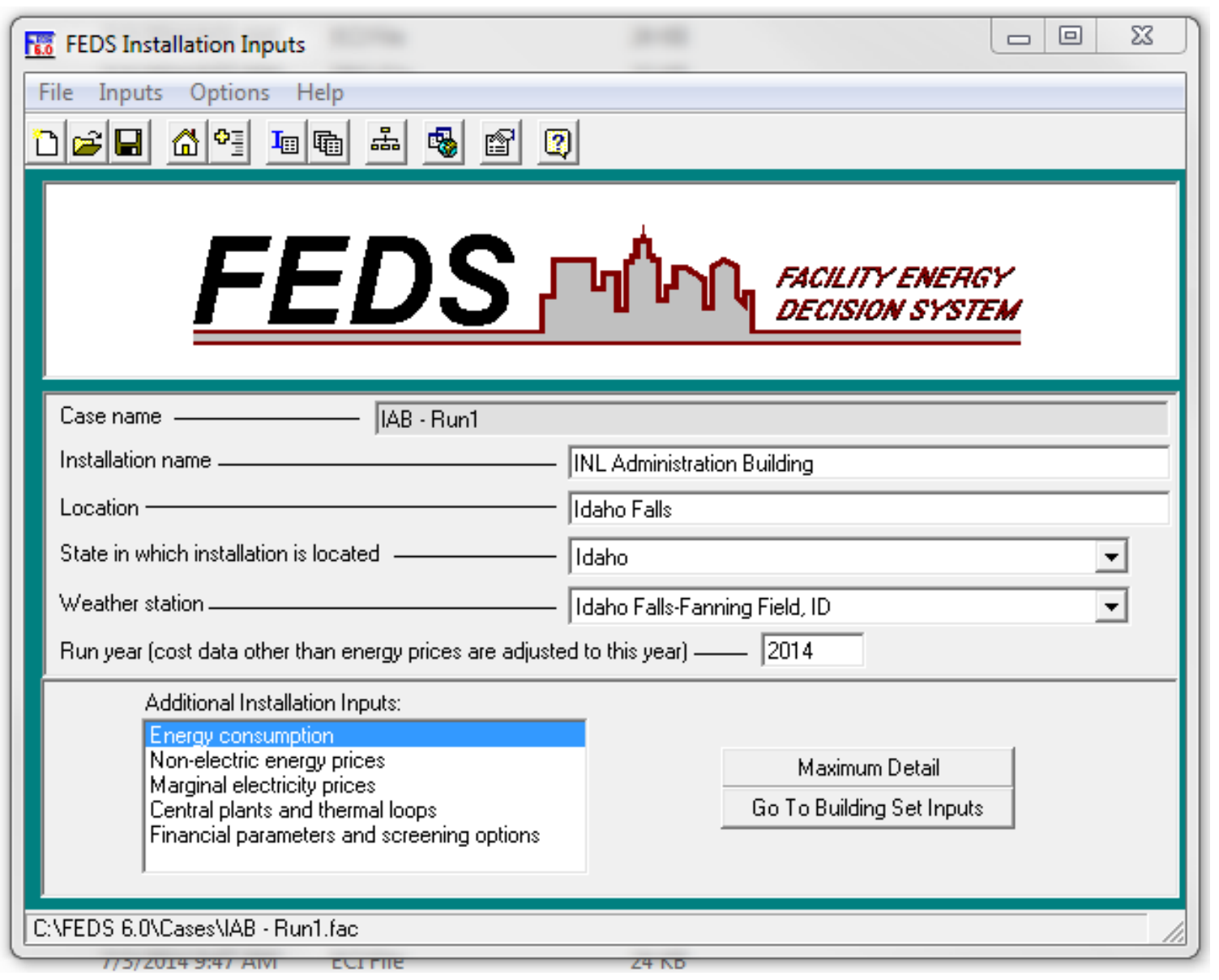

Figure 8. FEDS - Minimum Information (http://www.pnl.gov/feds/).

Users enter annual energy consumption and cost by fuel type as well as the per unit commodity prices. Other minimum data required includes building type (civilian, military), square footage, occupancy schedule, fuel types for heating, cooling, and hot water heating. This required information is similar to what the user would have previously entered into Portfolio Manager for benchmarking purposes.

Once the minimum information is entered, the user can expand the "Maximum Detail" to fill in additional information and operating parameters that more fully describe the building and its operations. "Maximum Detail" inputs are designated with a small locked padlock icon. These can be unlocked for data entry upon addition of all minimum required fields. The FEDS installation CD also includes additional forms to aid the user in collecting information during a walk through audit of the building.

FEDS requires users to understand the basic of building equipment (lighting, HVAC, hot water, motors), building envelope, and operating schedules (see Figure 9 and Figure 10). The tool includes pull-down menus that allow the user to select building equipment from prepopulated lists of equipment. The user also enters detailed information such as operating hours and equipment efficiency ratings. Users may enter as much or as little information beyond the minimum as they wish; however, the tool applies estimates and infers details the user does not enter. Thus, with more detailed information provided by the user, FEDS will be able to return more accurate and representative energy saving opportunities. 
Building Set Inputs: General Information

Building set identification

IAB

Description

Office and administration building

Building set 'Type' classification

Civilian: Office

Number of buildings in this set

1

Average construction year for buildings in this set

Total floor area for this building set [sq.ft.]

1985

How many Use-Areas are in this building set?

67725

Aspect ratio (north facing length / east facing length)

$\bar{x}_{1} \Gamma_{2}$

Solar normalization

1.436 量

Linked building set

[None

$\sqrt{\mathbf{X}}$ Calculate solar gains by facing directions

C Ignore facing directions

] Link Unlink

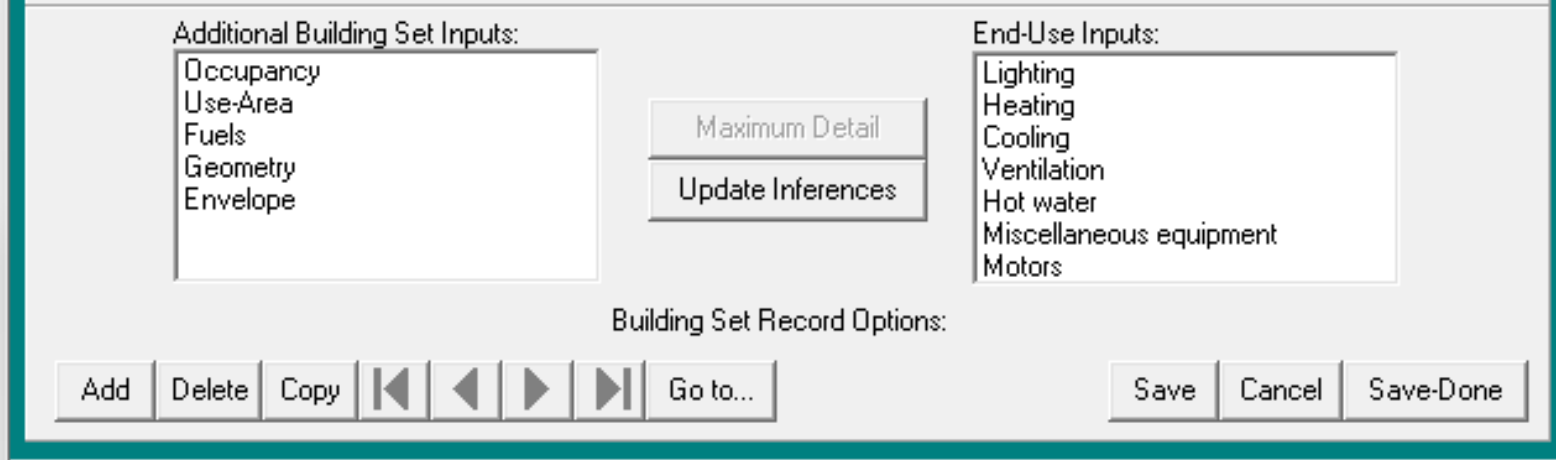

End-Use Inputs:

Bldg: [MAX][1 in 1] IAB

C:YFEDS 6.0VCasesl/AB - Run1.fac

Figure 9. FEDS - General Information (http://www.pnl.gov/feds/). 


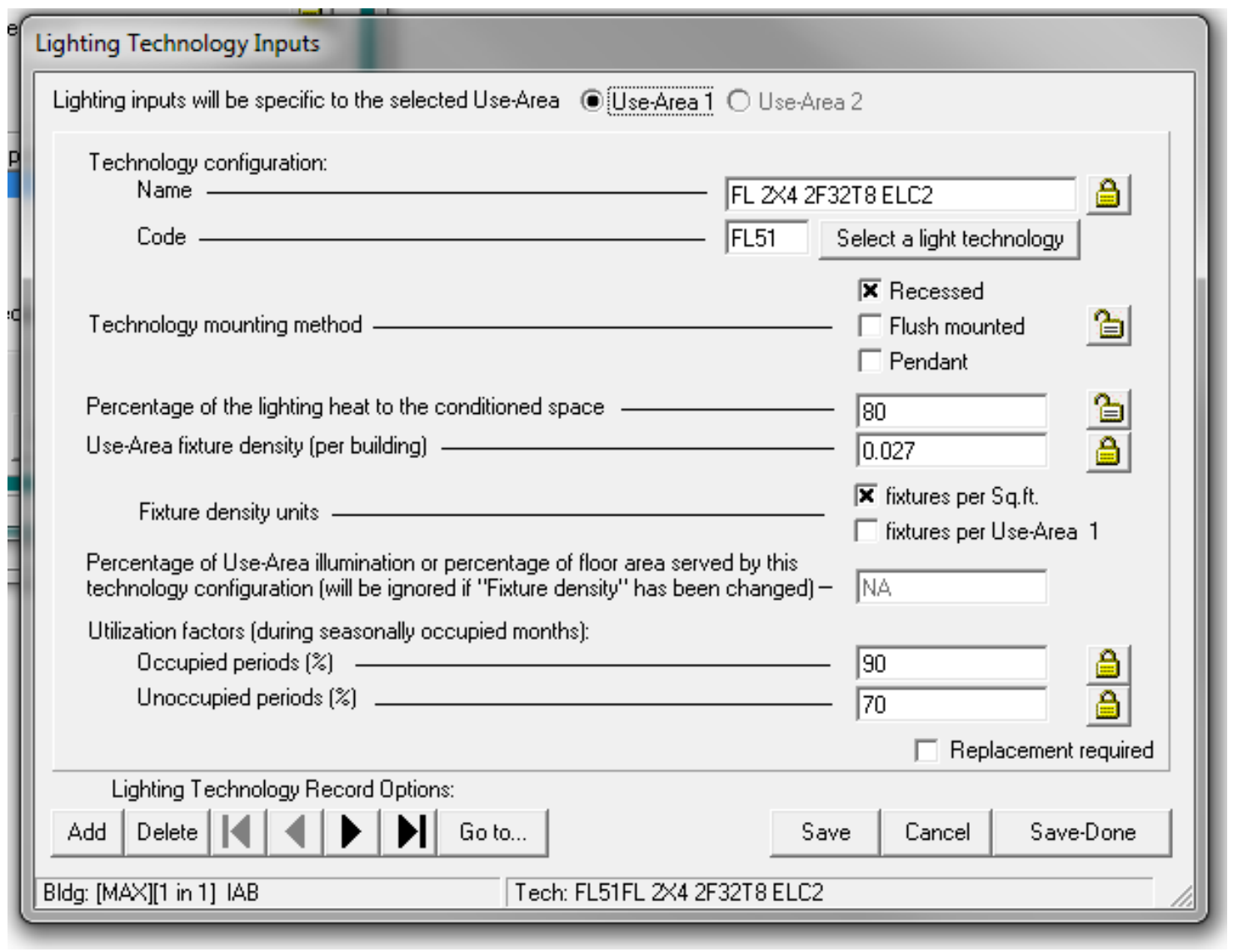

Figure 10. FEDS - Lighting Technology Inputs (http://www.pnl.gov/feds/).

\subsubsection{Analyzing Energy Conservation Measures}

After the building set information has been entered into FEDS, it is recommended the user calibrate the model against historic energy usage data to verify the model has captured information that accurately reflects the building equipment and operation. To speed up the calculations during the model calibration process, the user may exclude building sets from optimization. Using the option to excluding building sets from optimization prevents the FEDS software from automatically generating a list of possible retrofit technologies. The user can compare the energy consumption baseline from FEDS with the actual historic energy use from monthly energy consumption entered in Portfolio Manager and then refine the model until the baseline correlates well with historic usage.

Once the model is calibrated the user can run the FEDS model to obtain a listing of energy conservation opportunities. The FEDS software includes a database of retrofit alternatives in the following categories: heating, cooling, building envelope, service hot water, lighting, and motors. Currently, retrofit options are not available for ventilation system and miscellaneous equipment. FEDS generates a listing of suggested retrofit technologies that meet assigned financial criteria. Energy conservation opportunities automatically generated by FEDS are limited to those retrofit measures within the FEDS database.

Users also can select fuel types to be available or unavailable for retrofit options. For example, if there is no natural gas service to the building, the user can designate natural gas as unavailable; therefore, FEDS will not evaluate possible retrofit options that require natural gas. Alternatively, the user can elect to explore retrofit opportunities available should additional fuel sources be expanded to the site. 
Advanced users can alter the default retrofit cost and labor rates as well as emission factors to more accurately reflect rates and factors specific to their area should these significantly differ from the default values. With a little extra effort, advanced FEDS users can also manually run energy conservation opportunity scenarios (i.e., retrofit or schedule change) of their own design not in the FEDS retrofit options database.

Step 1. The user creates baseline model as a first case.

Step 2. Copy the first case and save it with a new unique name to create a second case. Then open the second case and change the inputs as desired to describe the energy conservation retrofit or schedule change.

Step 3. Run both cases and take the difference between the energy consumption of the "existing" scenarios from the first case and the second case to obtain the energy savings for the ECM. To speed up the calculations the user should select the option to exclude the building set from optimization.

\subsubsection{Reports and Output}

FEDS provides text output and comma separated variable files with detailed energy savings and financial analysis for the identified retrofit measures. In addition to energy reduction, the tool provides emission reductions, existing and post-retrofit energy intensity, first-year energy dollar savings, present value of life-cycle energy and operations and maintenance savings, and estimate cost for retrofits. One text file (see Figure 11) provides a summary of the building set energy and cost savings and a second text file details information on each retrofit option.

FEDS provides a detailed report including energy and cost savings for the identified retrofit opportunities. The report breaks down the energy consumption by fuel type and also end use. The economics of each retrofit opportunity is analyzed by FEDS and only those retrofits that meet the financial criteria are included in output reports. The output reports provide estimated project implementation costs and return on investment information as recommended in the EISA Guidelines.

\subsubsection{Commissioning}

The FEDS software could be used as an analysis tool in the commissioning process to calculate energy savings of operating schedules and other RCx recommendations. In using FEDS to calculate energy savings for RCx recommendations, "analyzing various what-if scenarios, can be modeled manually via changing parameters on the building or installation input screens and comparing resulting *.txs reports." (Facility Energy Decision System User's Guide Release 6.0) For example, an inspection identifies the building automation system (BAS) had been over-ridden and the HVAC system is operating 24 hours per day instead of operating from 5 a.m. to 7 p.m. as stated in the HVAC operation specifications. Here is how FEDS could be used to calculate the energy savings for reinstating the schedule in the BAS:

Step 1. The user creates a first case with the HVAC system operating 24 hours per day.

Step 2. Copy the first case and save it with a new unique name to create a second case. Then open the second case and change the input for the HVAC system operating schedule to reflect the 5 a.m. to 7 p.m. operating schedule.

Step 3. Run both cases and take the difference between the energy consumption of the "existing" scenarios from the first case and the second case to obtain the energy savings for reinstating the HVAC operating schedule. 


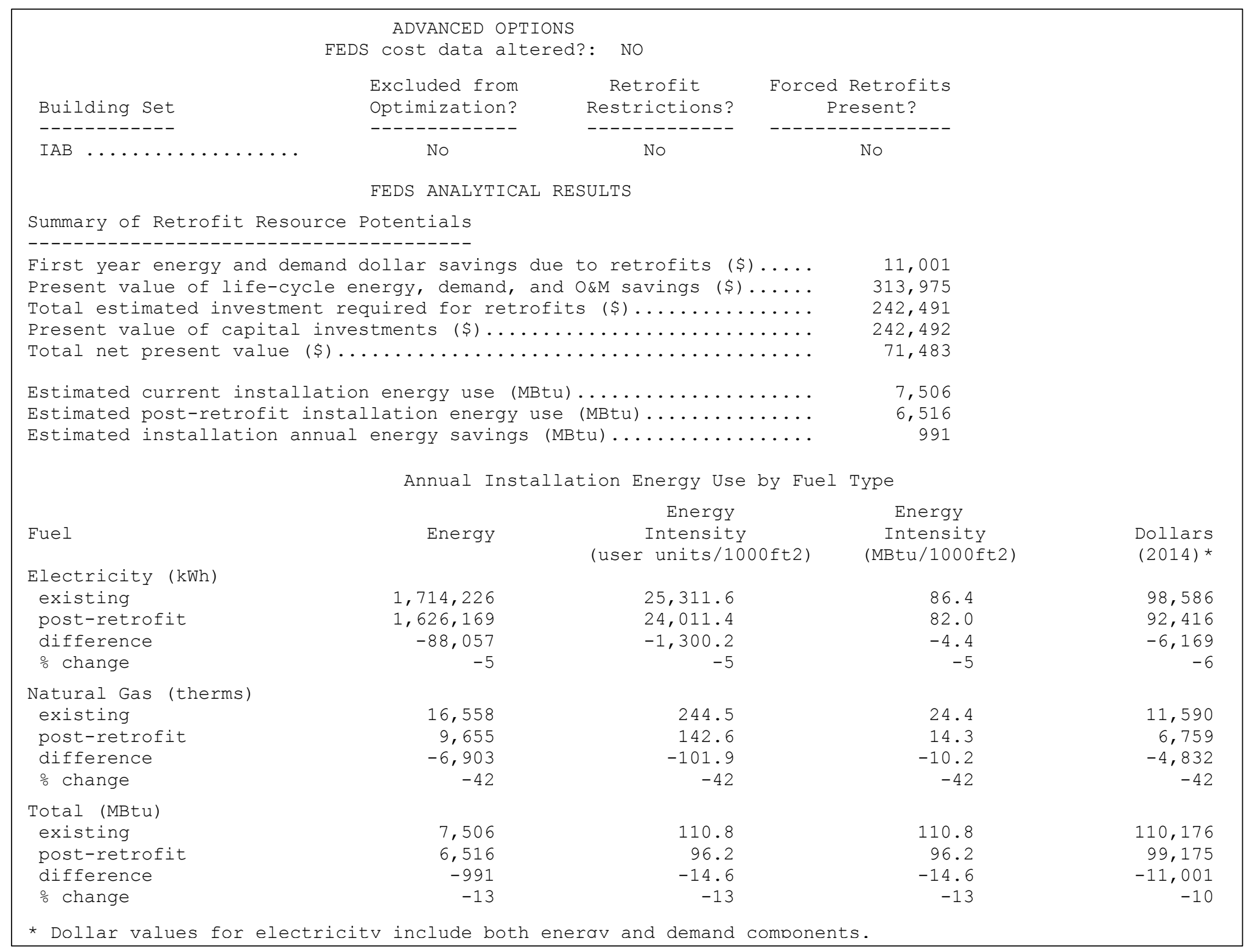

Figure 11. FEDS - Output. 


\section{4 eQUEST $^{\circledR}$}

\subsubsection{Software Tool Summary}

The eQUEST ${ }^{\circledR}$ energy modeling tool, developed by James J. Hirsch \& Associates, runs the DOE-2 energy simulation engine developed by James J. Hirsch \& Associates in collaboration with Lawrence Berkeley National Laboratory. (Welcome to DOE2.com) DOE-2 performs hourly energy calculations to simulate the energy consumption of buildings. eQUEST is one of a number of desktop computer front end interfaces for DOE-2.

"eQUEST is a sophisticated, yet easy to use building energy use analysis tool which provides professional-level results with an affordable level of effort.

eQUEST allows you to perform detailed analysis of today's state-of-the-art building design technologies using today's most sophisticated building energy use simulation techniques but without requiring extensive experience in the "art" of building performance modeling. This is accomplished by combining a building creation wizard, an energy efficiency measure (EEM) wizard and a graphical results display module with an enhanced DOE-2-derived building energy use simulation program. " (eQUEST ... the QUick Energy Simulation Tool Overview)

eQUEST is available for computers using the Windows $8 / 7 / \mathrm{Vista} / \mathrm{XP}$ operating systems and can be downloaded from the DOE2.com website.

Website: $\quad$ http://www.doe2.com/equest/

Cost: $\quad$ Free

Version: $\quad 3.65$ build 7163

Energy Audit Type: Level II/Level III

\subsubsection{Using the Software Tool When Performing an Energy Audit}

eQUEST requires detailed information for each of the building components and operating schedules. The accuracy of the simulation model output is improved as a greater amount of information on equipment and operating schedules is entered. Information can be gathered from building architectural, mechanical, and electrical drawings and equipment schedules; onsite visits to inventory equipment and building conditions; and conversations with building operators.

A building energy model is created by describing the building components, operating parameters, and equipment fuel types. Building components include building envelope constructions such as walls, windows, roof; HVAC systems; plug loads; lighting, etc. The operating parameters include occupancy schedule, lighting schedule, thermostat settings, heating and cooling months, etc. The calculation engine will use these data to simulate the energy consumption of the building. A Wizard function (see Figure 12) walks the user through a series of screens to enter the building envelope, HVAC equipment, lighting, office and miscellaneous equipment load, operating schedules, and utility rate information. 


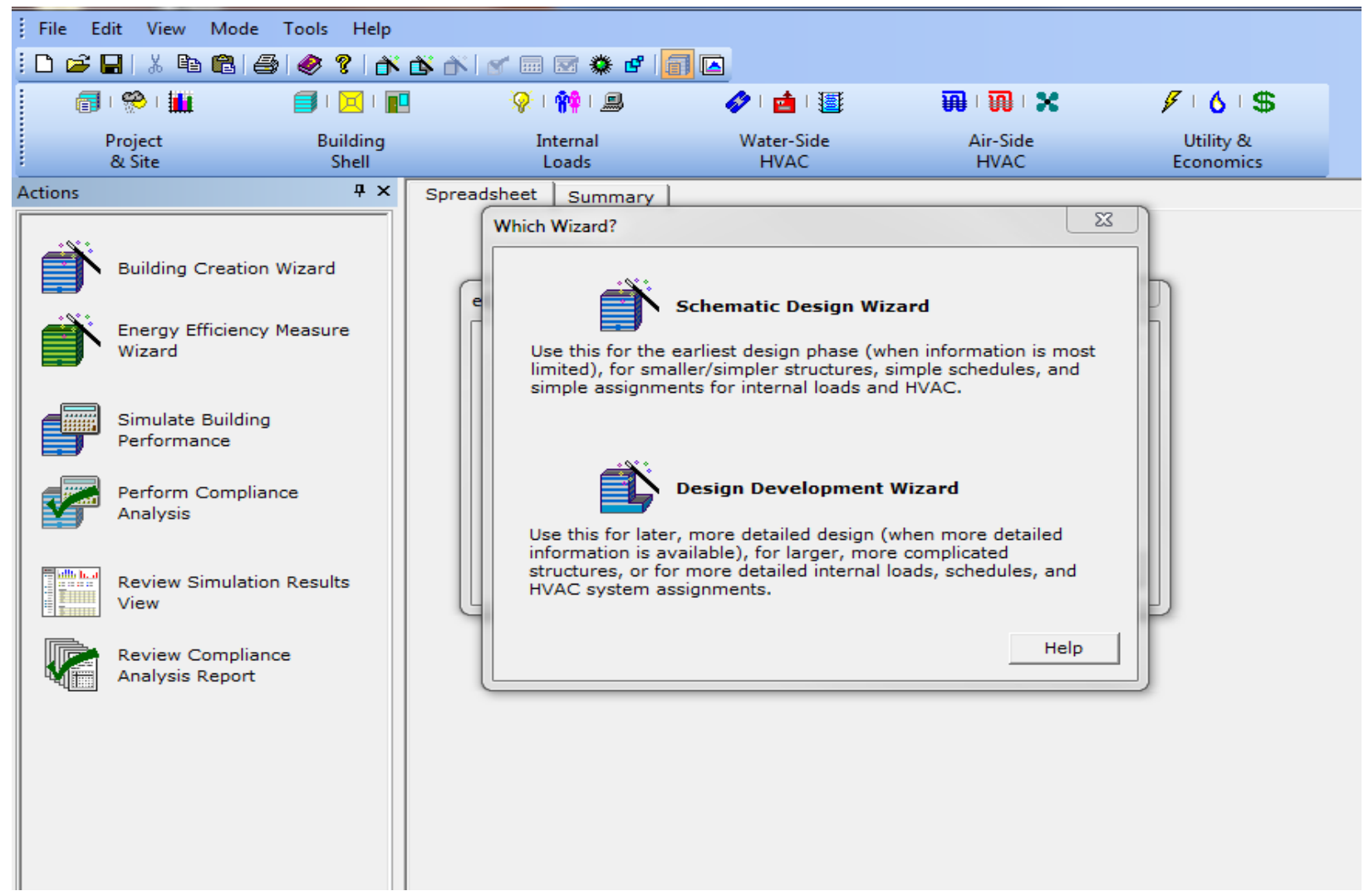

Figure 12. eQUEST - Design Wizard Menu (http://www.doe2.com/equest/).

When creating a model eQUEST offers two design wizards - "Schematic Design Wizard" for simple structures and limited building information and "Design Development Wizard" for more complicated structures and detailed information availability - to aid users in creating the building simulation model. Each wizard walks the user through a series of input screens in the following categories (see Figure 13

- Project/Site/Utility

- Building shell

- Air-side systems

- Packaged HVAC equipment (as applicable)

- Chilled water plant (as applicable)

- Hot water plant (as applicable)

- Water and ground source heat pumps (as applicable)

- Domestic hot water.

The screens offer pull-down menus for selecting building equipment and fields to enter building operating schedules. 


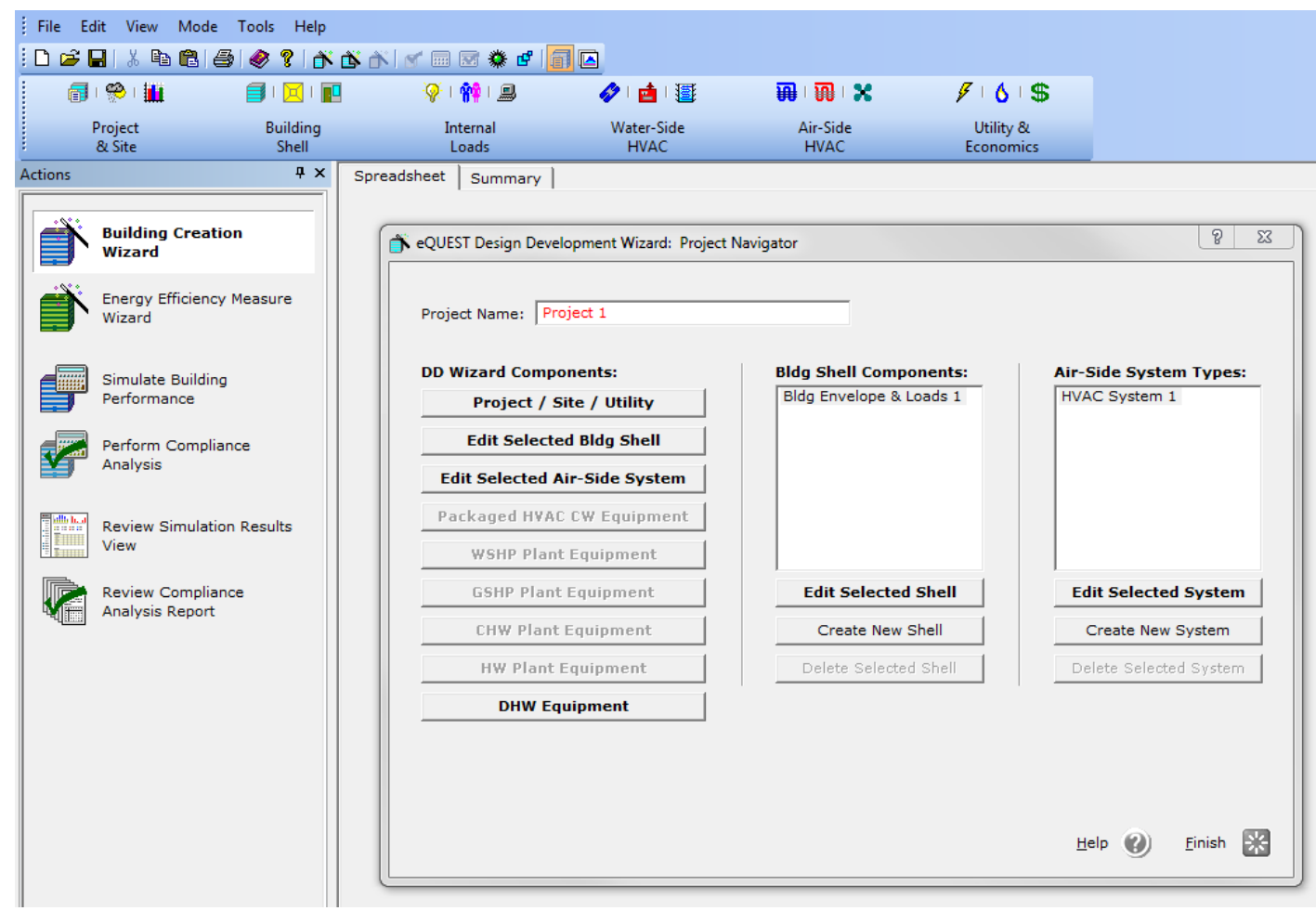

Figure 13. eQUEST - Using a Design Wizard (http://www.doe2.com/equest/).

After completing all of the screens of the Wizard, aspects of the finished model can be viewed such as the building layout (2-D and 3-D views), HVAC systems, internal loads, and utility information (see Figure 14). 


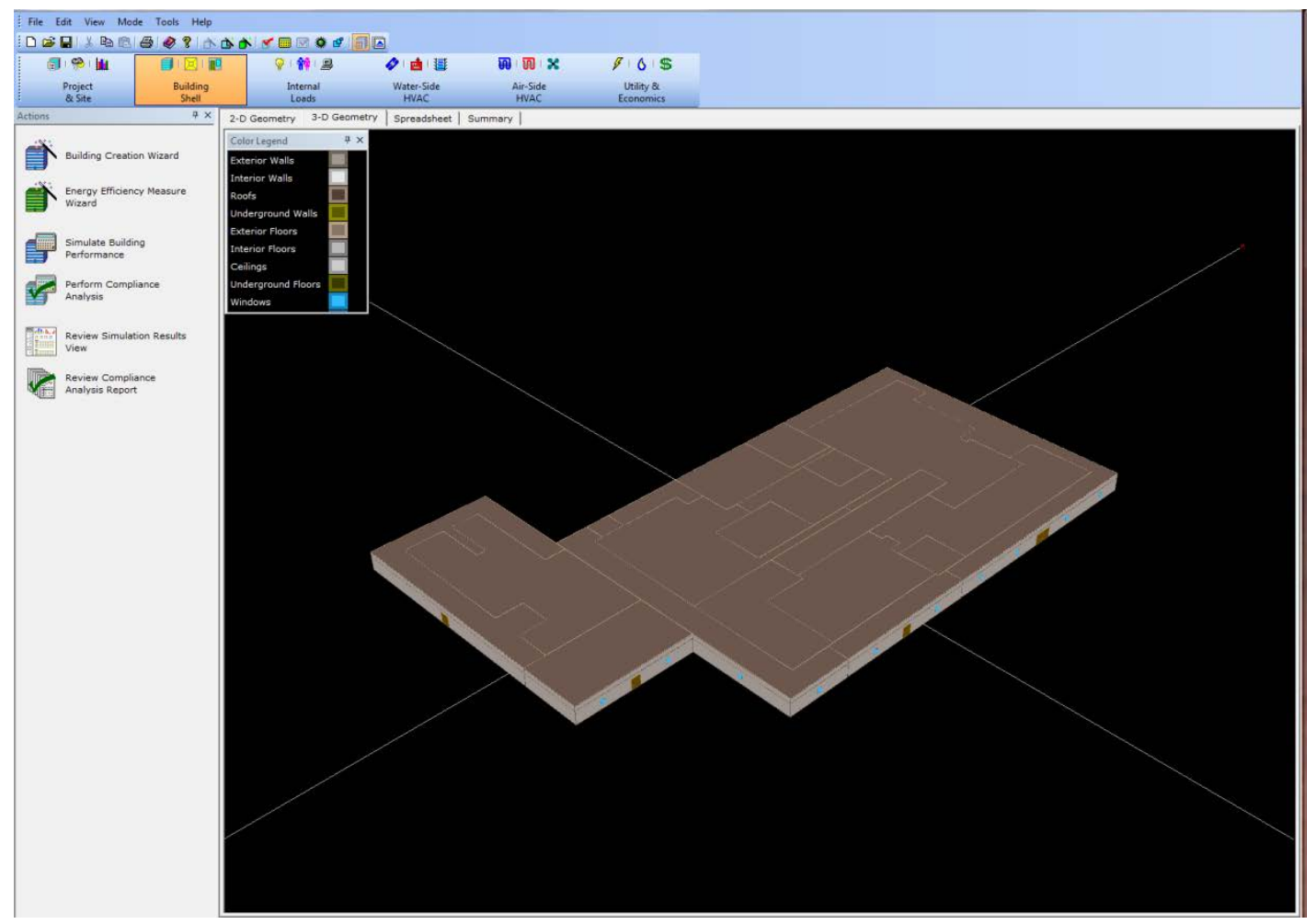

Figure 14. eQUEST - Building Model 3-D View (http://www.doe2.com/equest/).

eQUEST displays building system information in both a graphical and table format (see Figure 15 and Figure 16). The data is color coded in the table format with default values shown in green and user entered values shown in red.

The user may re-open the Design Wizard and make changes to refine the model and schedules, or advanced users may make edits through the design table or graphical interface. However, any changes made outside of the Design Wizard will need to be saved as a new project. These changes do not get translated back to the project originally created in the Design Wizard, which is important to note if the user wishes to use eQUEST's built-in "Energy Efficiency Measure Wizard."

Once the building model is complete, the user should calibrate the model by comparing the energy output from the model with the monthly energy consumption entered for benchmarking into Portfolio Manager. If the model energy is too high or too low compared with the Portfolio Manager benchmarking data, then the user will need to review and refine the model input until the model energy correlates with the historic energy consumption of the building. 


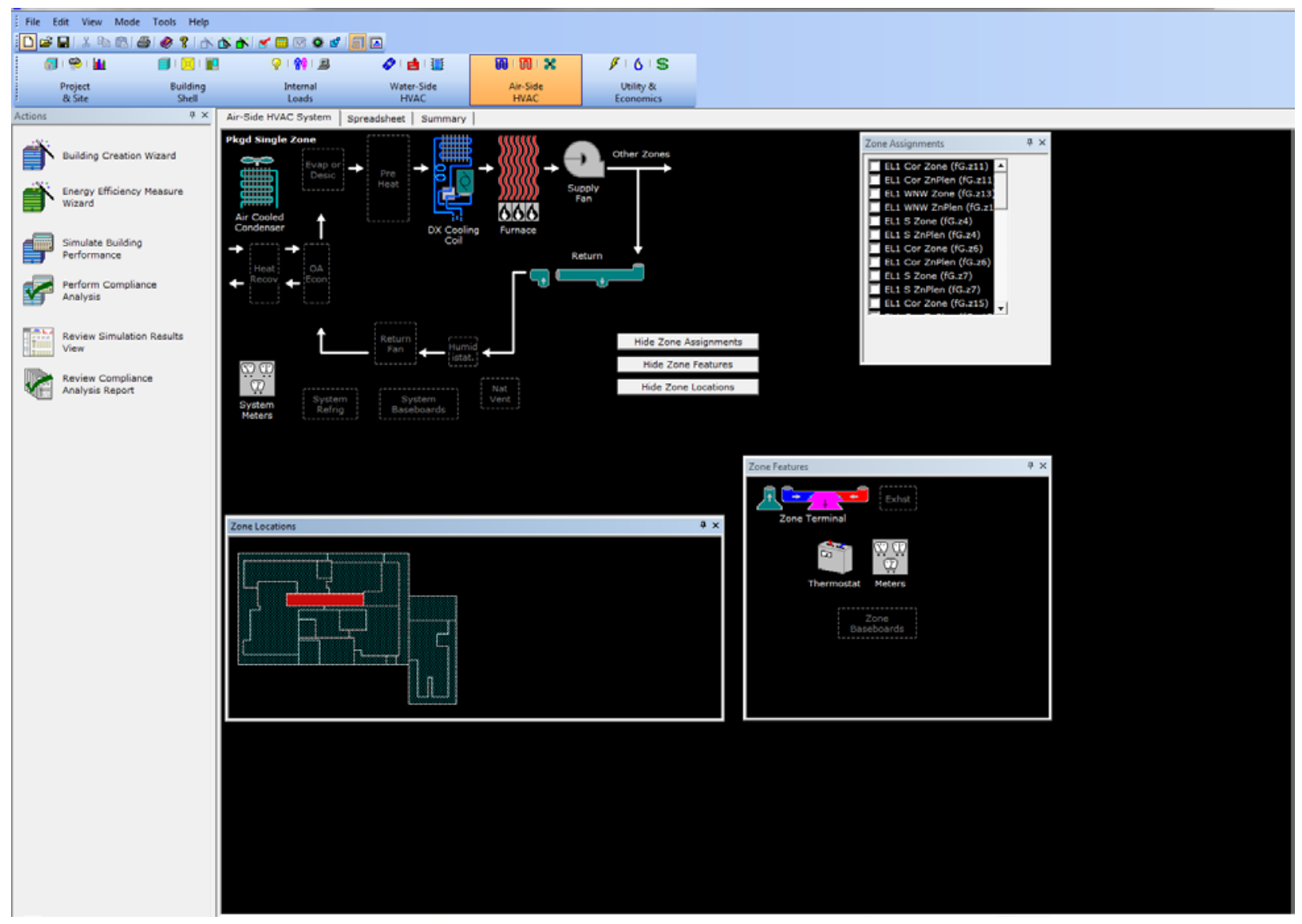

Figure 15. eQUEST - HVAC Systems (http://www.doe2.com/equest/).

Depending on the size and complexity of the building and systems, a model can be created in eQUEST in a half a day for simple buildings or may take several days for large, complex buildings. Users should have a strong background in building systems or engineering to most fully take advantage of the powerful and sophisticated nature of building simulation modeling programs such as eQUEST.

Advanced users can enter and edit information outside of the Design Wizard for individual components that make up the building shell (construction layers, windows, roof, doors, plenum); internal loads (lighting, office equipment, plug loads); air-side HVAC systems (preheat coil, supply fan type, cooling coil, heating coil, economizer, return fan); and water-side HVAC systems (chillers, boilers, heat pumps). Thus, the tool requires a strong understanding of HVAC systems and their controls. 


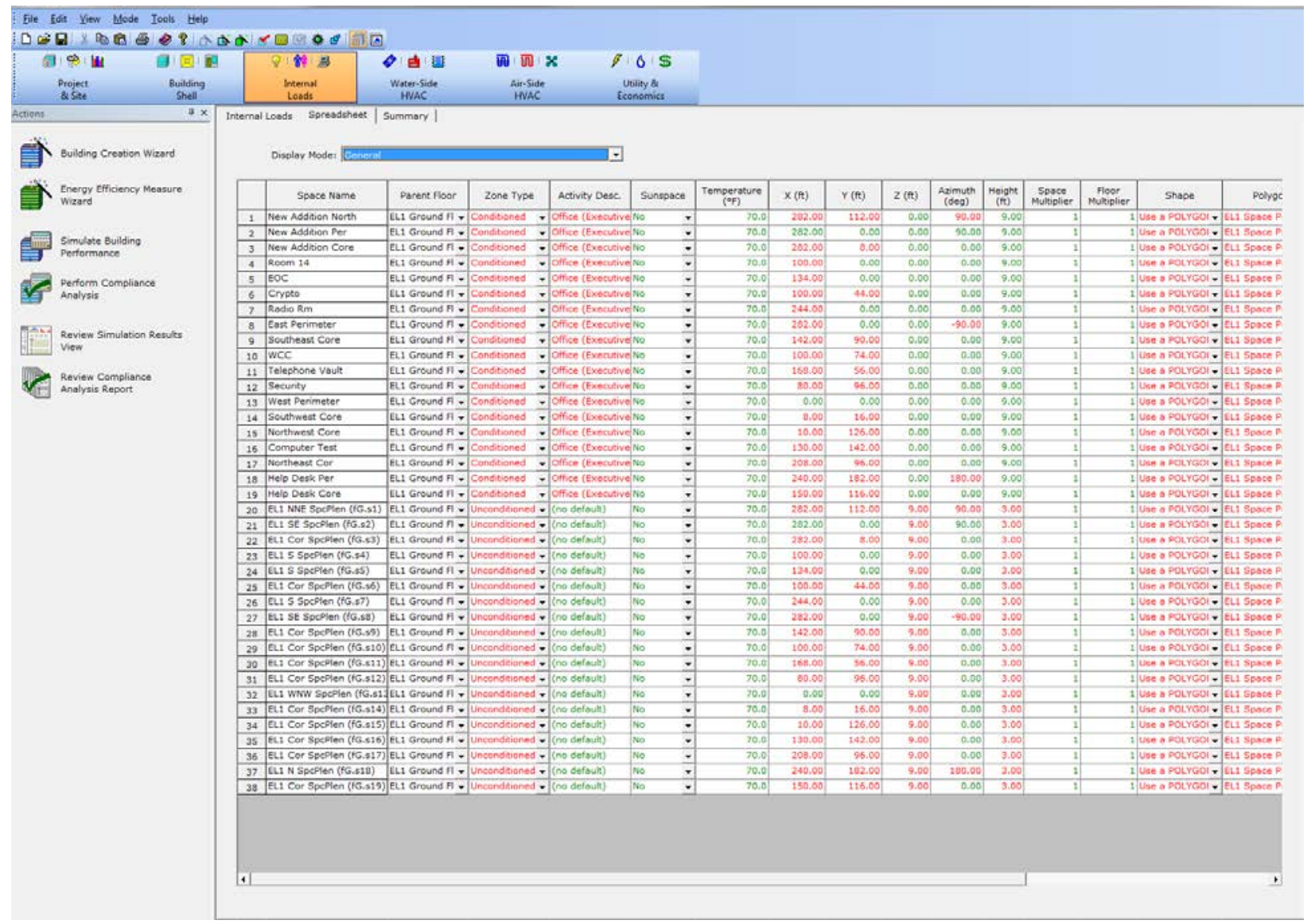

Figure 16. eQUEST - Model Data Table (http://www.doe2.com/equest/).

\subsubsection{Analyzing Energy Conservation Measures}

Once the model is created in eQUEST, the user can calculate savings achieved by energy efficiency measures by making changes to the building equipment, operating schedules, and other parameters of the model. Users should have a strong background and knowledge of building systems and operation to allow them to develop ECM ideas and use eQUEST to evaluate energy savings.

eQUEST includes an Energy Efficiency Measure Wizard that works with the model created via the Design Wizard (see Figure 17). The Energy Efficiency Measure Wizard aids the user in creating a parametric analysis in the categories of building envelope, internal loads, HVAC systems, domestic hot water, and whole site/building. The Wizard can run each ECM separately or group ECMs together as a single project. The user has the ability to enter life cycle cost data such as first cost and annual maintenance cost for each ECM or project, which will allow eQUEST to calculate the financial and payback information to aid in determining feasibility of the project and as required in the EISA audit report. Performing a parametric analysis allows the user to look at "what if" scenarios to quickly investigate the feasibility of many energy conservation measure ideas and find those measures that best meet the energy savings, ROI, and other financial goals of the institution. 


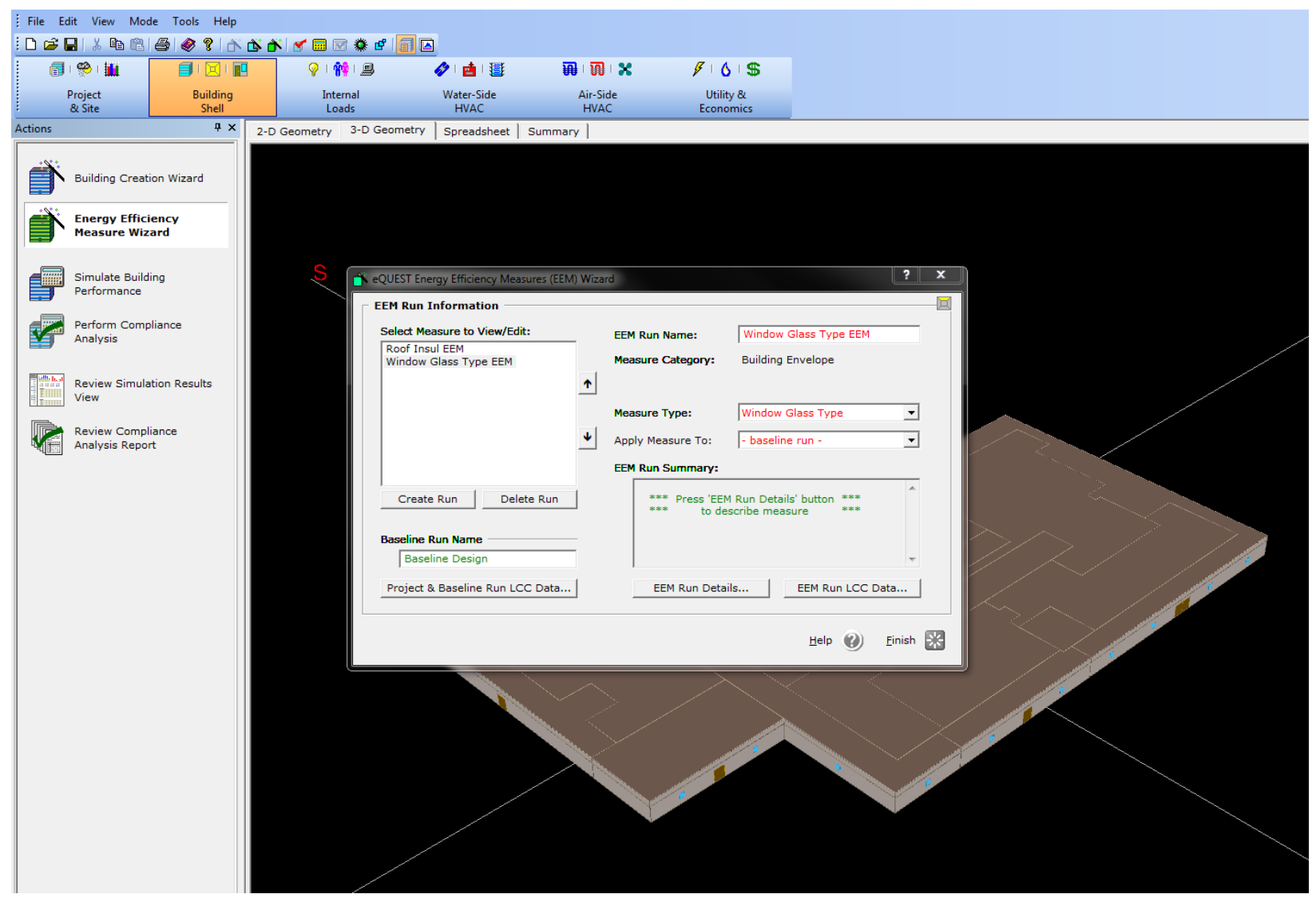

Figure 17. eQUEST - Energy Efficiency Measure Wizard (http://www.doe2.com/equest/).

Advanced users can develop their own parametric analysis by changing parameters of the model outside of the Wizard (such as equipment type and efficiency ratings and operating schedules) and comparing the output from the various model runs.

\subsubsection{Reports and Output}

eQUEST provides several types of output reports viewable within the program (see Figure 18), such as Single-Run Reports that provide a breakdown of energy consumption for a single baseline; ECM-Run Comparison Reports that list energy and cost savings for a group of runs; and Parametric Run Reports that present the "energy used" and financial information for each run in a parametric analysis. The reports feature both graphs and tables and can be printed or exported as PDFs. In addition, eQUEST also generates all of the traditional DOE-2 text output files (.sim).

Since eQUEST is an energy simulation software tool, the program calculates hourly energy consumption for the building and breaks down energy consumption by end use. The user is able to see how proposed energy conservation measures impact energy consumption of other building systems (commonly called interactive effects). 


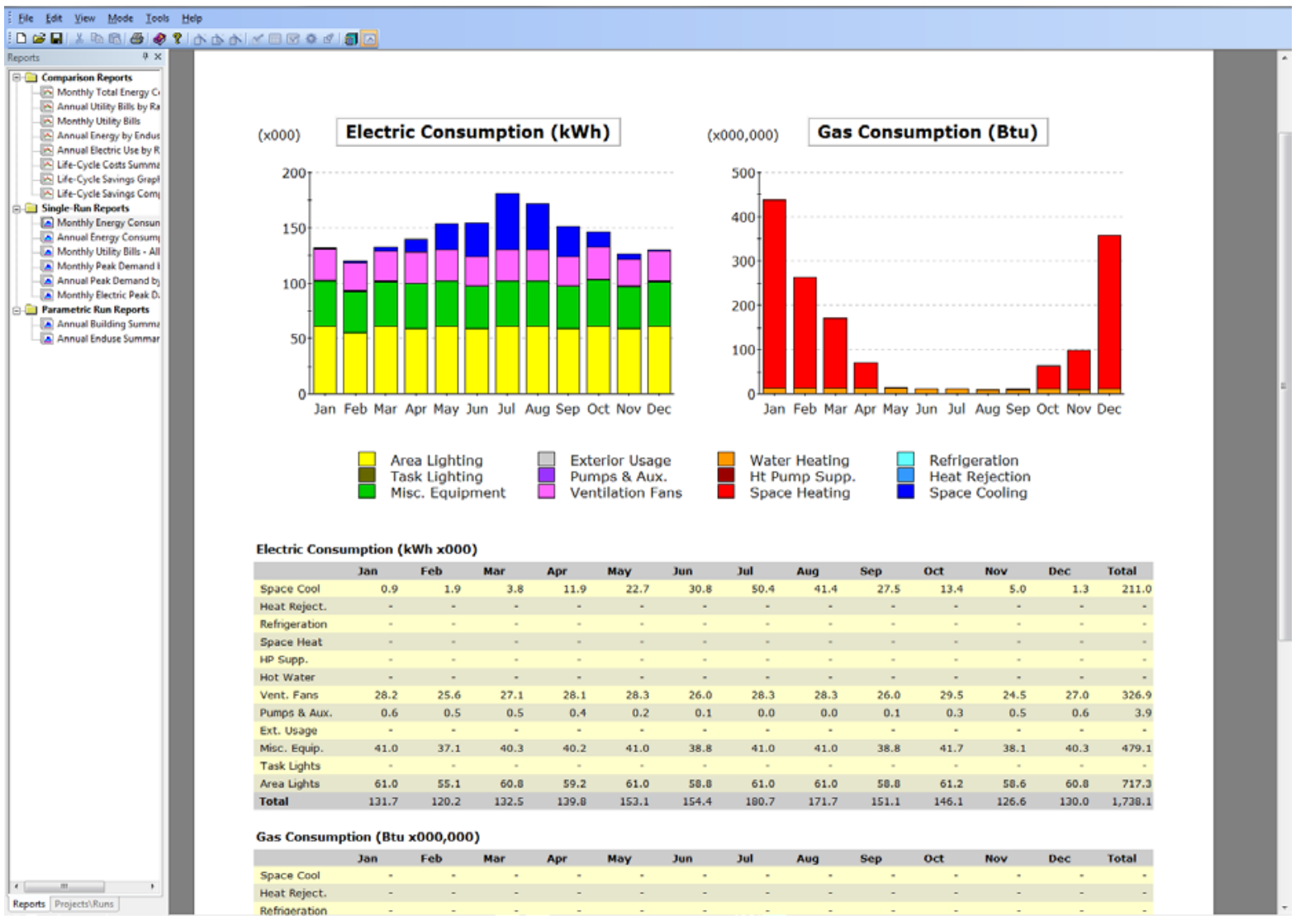

Figure 18. eQUEST - Single-Run Reports and Output (http://www.doe2.com/equest/).

The detailed information available from the reports and output would be applicable for an ASHRAE Level III, or investment grade, audit. eQUEST provides simple payback, discounted payback, savings to investment ratios (SIR), and adjusted internal rates of return life-cycle cost information if the user enters one-time implementation costs.

\subsubsection{Commissioning}

The flexibility for setting operating schedules and equipment metrics make eQUEST a powerful tool for calculating energy savings from implementing operating changes identified through commissioning/retro-commissioning.

\section{5 simuwatt $^{\mathrm{TM}}$ Energy Auditor}

\subsubsection{Software Tool Summary}

The tablet and web-based tool, simuwatt ${ }^{\mathrm{TM}}$ Energy Auditor, enables real-time creation of a building model during an onsite energy audit. The tool reduces the need for hand written note taking by allowing the user to access the National Renewable Energy Laboratory's (NREL) Building Component Library (BCL) while in the field to catalog building equipment. simuwatt was developed by NREL and concept3D and supports the hourly energy simulation engine EnergyPlus and NREL's OpenStudio software. Some of the features of simuwatt include:

- Connected iPad and Web interfaces to support desk and field data entry 
- Flexible data inputs for varying levels of audits and supporting outputs for analysis, spreadsheets, and OpenStudio energy models

- Support for multiple auditor site visits.

"EnergyPlus is an energy analysis and thermal load simulation program. Based on a user's description of a building from the perspective of the building's physical make-up and associated mechanical and other systems, EnergyPlus calculates heating and cooling loads necessary to maintain thermal control setpoints, conditions throughout a secondary HVAC system and coil loads, and the energy consumption of primary plant equipment. Simultaneous integration of these - and many other - details verify that the EnergyPlus simulation performs as would the real building." (EnergyPlus Energy Simulation Software) EnergyPlus was developed jointly by the University of Illinois at Urbana-Champaign and Lawrence Berkeley National Laboratory under funding from the U.S. Department of Energy.

"OpenStudio is a cross-platform (Windows, Mac, and Linux) collection of software tools to support whole building energy modeling using EnergyPlus and advanced daylight analysis using Radiance. "OpenStudio also gives the modeler integrated access to data from the Building Component Library. The ParametricAnalysisTool lets users modify a baseline OpenStudio model using OpenStudio measures to produce design alternatives." (OpenStudio) OpenStudio was developed by the National Renewable Energy Laboratory. simuwatt Energy Auditor

Website: $\quad$ http://simuwatt.com/

Cost: $\quad$ Fee based

Version reviewed: Beta

EnergyPlus

Website: $\quad$ www.energyplus.gov

Cost: $\quad$ Free

Version reviewed: $\quad 8.1$

OpenStudio

Website: $\quad$ https://openstudio.nrel.gov/

Cost: $\quad$ Free

Version reviewed: $\quad 1.4$

Energy Audit Type: Level II / Level III

\subsubsection{Using the Software Tool When Performing an Energy Audit}

"simuwatt Energy Auditor integrates a cloud-based library of energy conservation data, an established whole-building energy simulation engine, and advanced building geometry-capture software into a single tablet-based tool" (Newsroom: NREL Brings

Precision, Savings to Energy Audits) (see Figure 19).

Traditional energy simulation modelling requires the user to import computerized building drawing images and/or manually enter building wall and window measurements taken from hard copies of blueprints. simuwatt offers the unique ability to overlay an electronic copy of the building floor plan onto aerial and exterior views of the building from popular map tools to create the building geometry for the simulation model. Tablet users can then quickly designate the building's HVAC zones using the tablet touch screen. 


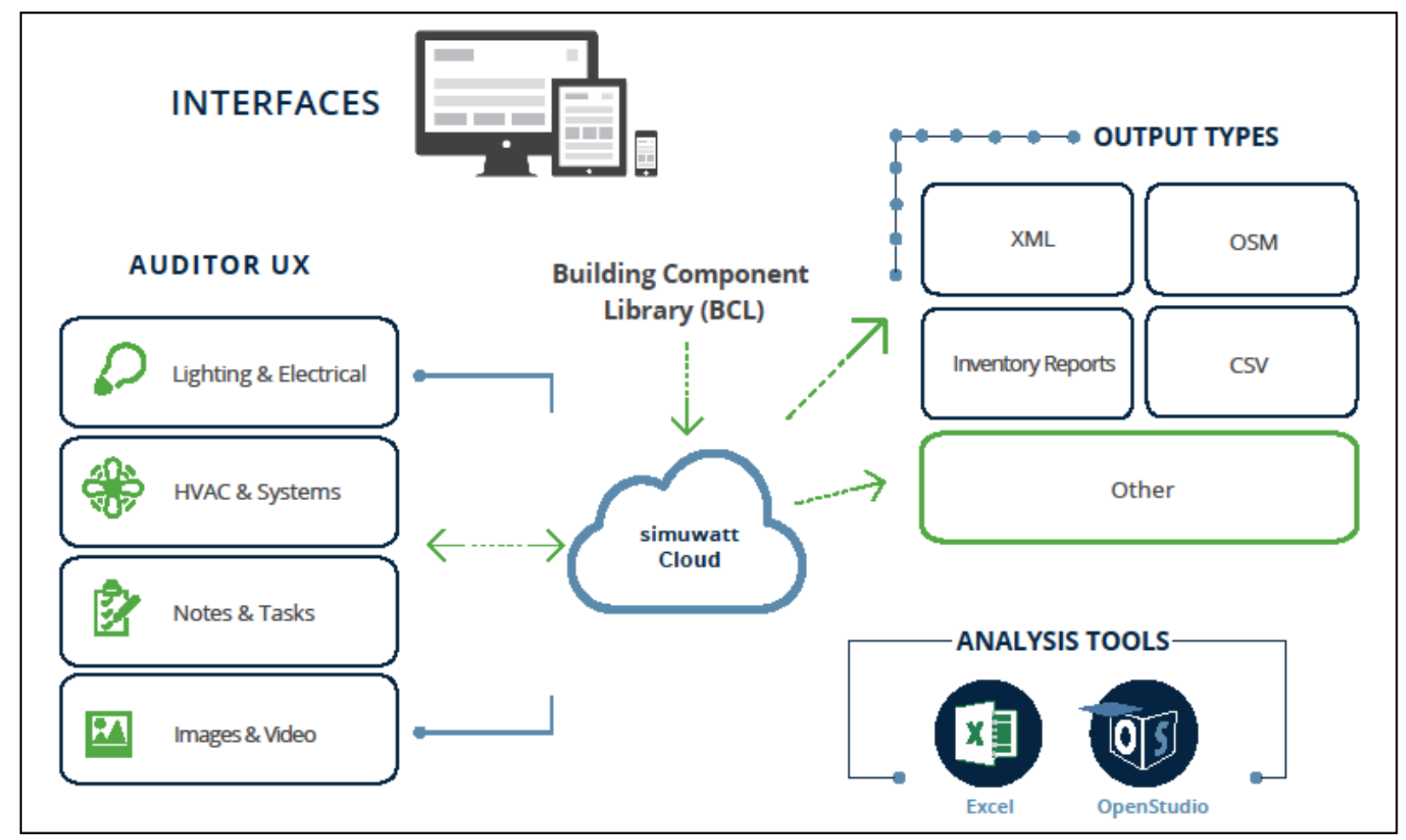

Figure 19. simuwatt - Structure (http://simuwatt.com/).

When conducting an audit onsite, the user can employ the tablet's camera to capture and store photographs of building equipment and add notes within simuwatt. Notes can be added to photos, which can be stored for later use. This creates a record documenting existing equipment and conditions. The user can also access NREL's Building Component Library (BCL) to build the energy model as the energy audit is in progress (see Figure 20).

Users work through a series of screens to define the building location and construction; occupancy and equipment operating schedules; internal loads such as lighting, computers, office equipment and other plug loads, HVAC zones and air side, and chilled and hot water systems. The menu-driven BCL aids users in entering accurate building information and is especially useful for systems such as lighting components. 


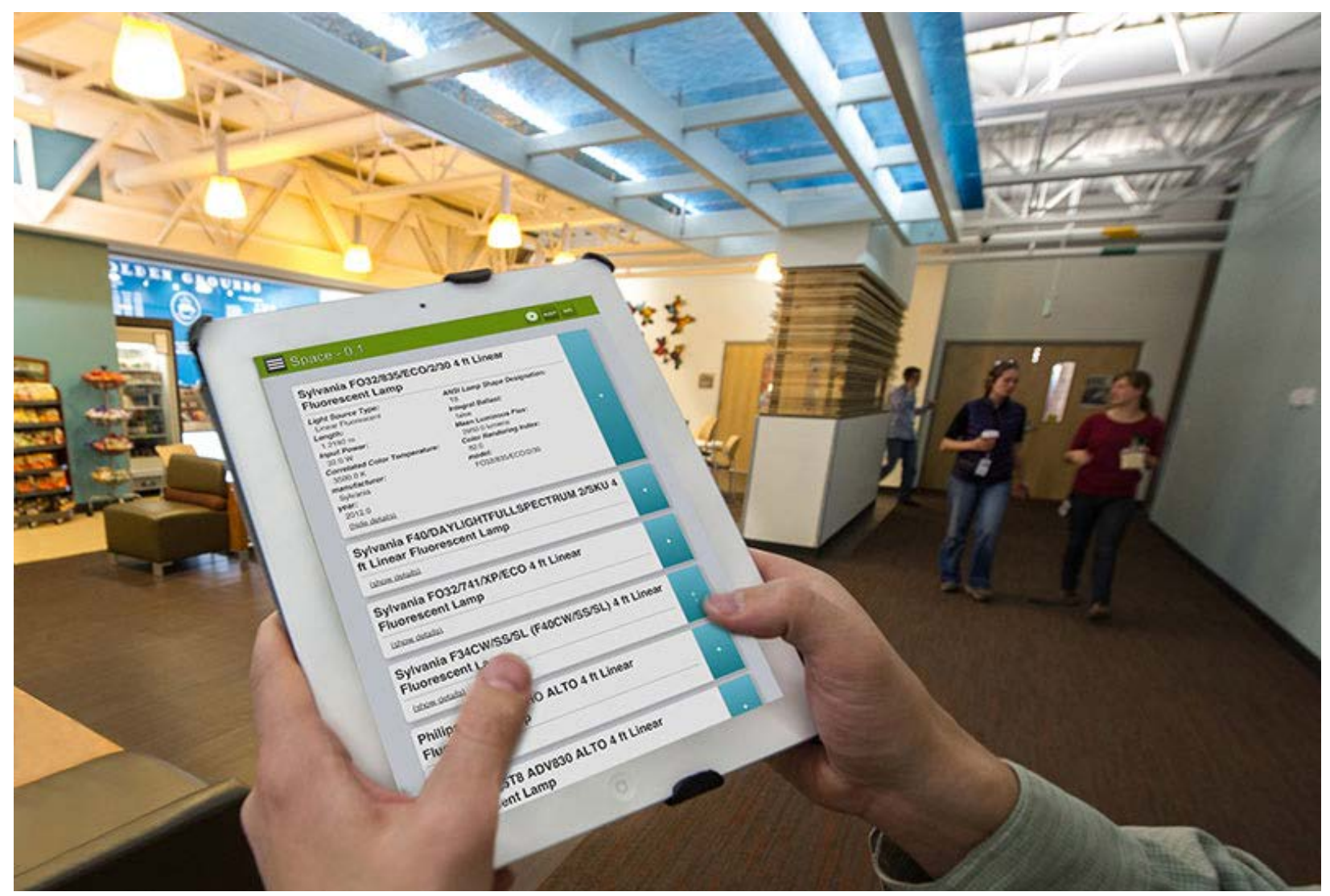

Figure 20. simuwatt - Using the Building Component Library (Photo credit: Dennis Schroeder http://www.nrel.gov/news/features/feature detail.cfm/feature $\mathrm{id}=4300$ ).

simuwatt builds the energy simulation model as the user enters the information during the onsite walk through and the model and data are uploaded to the Cloud for storage. Since the user is simultaneously conducting an energy audit and creating the energy simulation model, the user should have a strong knowledge of building operations and equipment.

Monthly energy consumption from the building used for benchmarking in Portfolio Manager should be used to calibrate the model by comparing the energy output from the model with the monthly energy consumption. Comparing the model energy output with the monthly energy consumption data in Portfolio Manager will aid the user in refining the model inputs to more accurately reflect the operation of the building.

Depending on the size and complexity of the building and systems, an audit can be completed and a model can be created in a day for simple buildings or may take several days for large, complex buildings. To fully take advantage of the powerful and sophisticated nature of building simulation modeling programs, such as simuwatt, the user should have a strong background in building systems or engineering.

\subsubsection{Analyzing Energy Conservation Measures}

The energy model created by simuwatt can be exported in OpenStudio (.osm) format where the user can run the simulation model and perform parametric analysis. Using OpenStudio, the user can toggle between screens for site, schedules, constructions, loads, space types, building stories, facility, thermal zone, and HVAC systems. OpenStudio allows the user to drag and drop components from the library (see Figure 21). 


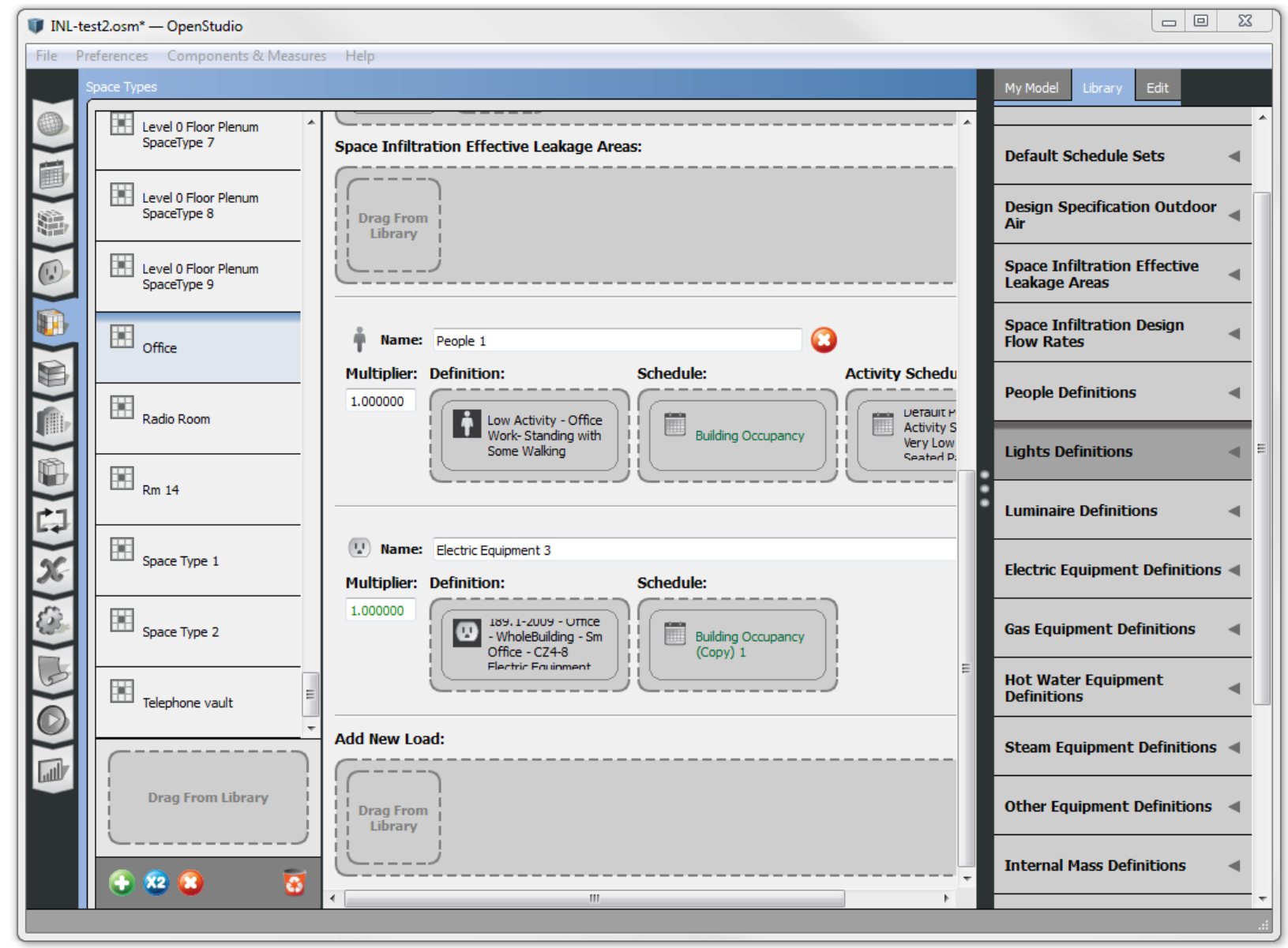

Figure 21. simuwatt model in OpenStudio - Space Types (https://www.openstudio.net/).

OpenStudio includes a Parametric Analysis Tool (see Figure 22) that allows users to perform "what if" scenarios investigating energy efficiency opportunities and measures. The Parametric Analysis Tool includes access to a library of measures housed in the BCL or created by the user. Measures are dragged and dropped from the Measure Library and can be grouped together as a project or run separately. Performing a parametric analysis allows the user to investigate feasibility of many energy conservation measure ideas to find those measures that best meet the energy savings, payback, and other financial goals of the institution.

The Measure Library speeds the parametric analysis by utilizing the BCL which allows registered users to both download ECMs and building components and upload ECMs and components to share with a group or the public. 


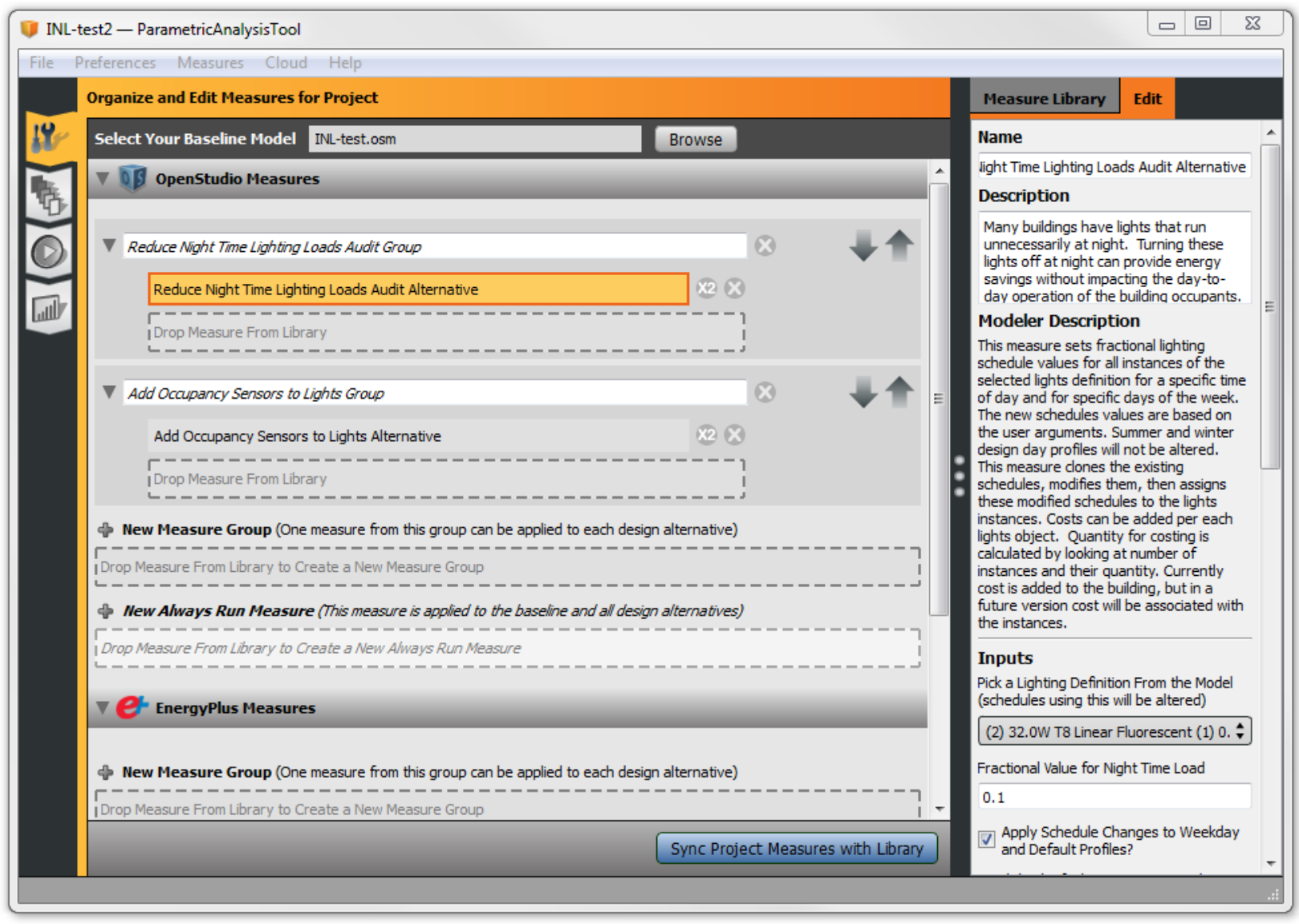

Figure 22. simuwatt model in OpenStudio - Parametric Analysis Tool - Measure Library (https://www.openstudio.net/).

From the results of the parametric analysis (see Figure 23) the energy manager can evaluate the energy savings and life-cycle cost information and determine the ECMs that best fit the energy savings goals and financial criteria of the facility. 


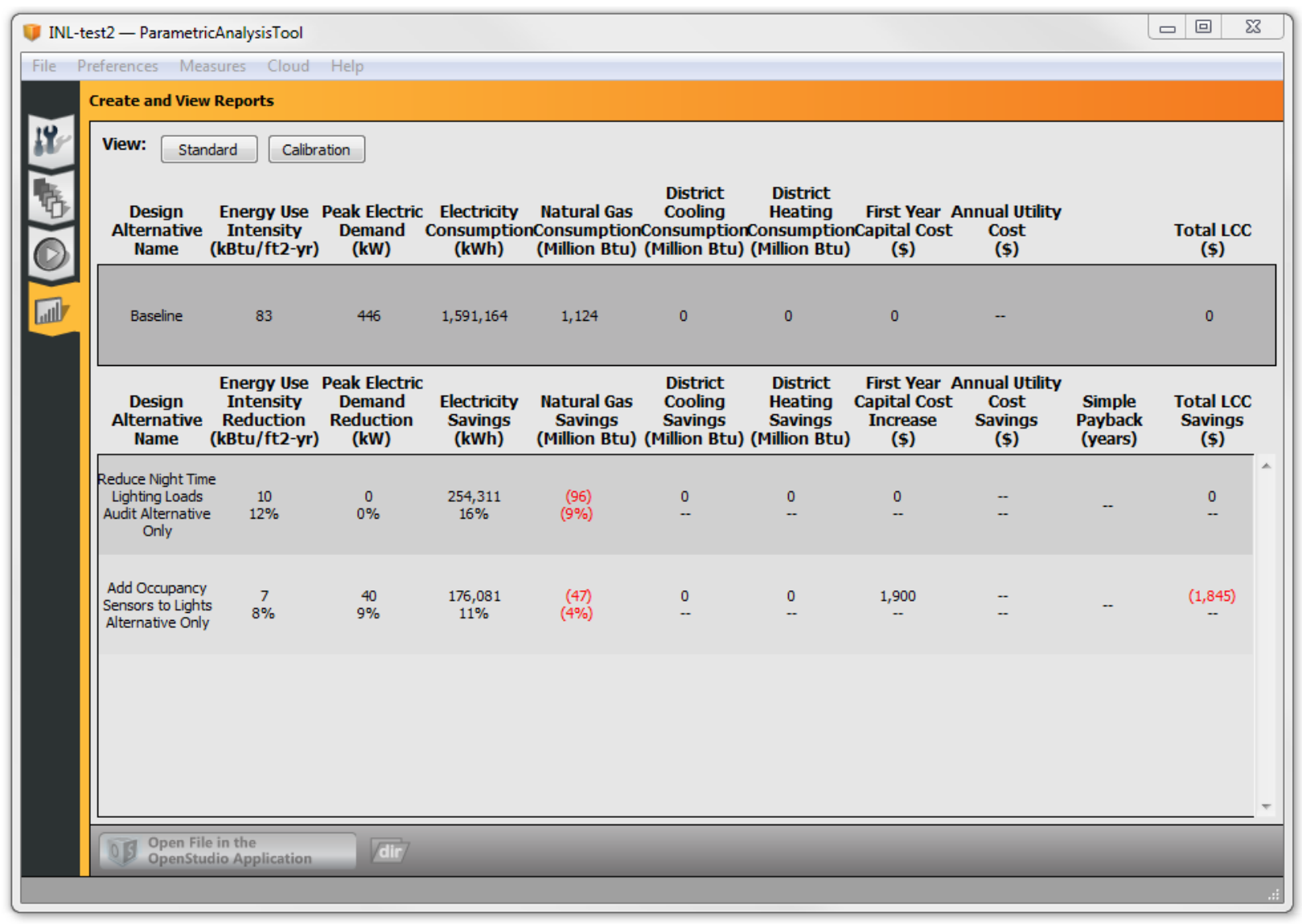

Figure 23. simuwatt model in OpenStudio - Parametric Analysis Tool Results (https://www.openstudio.net/).

\subsubsection{Reports and Output}

The hourly energy simulation provides a breakdown of energy consumption by system and fuel type. The software produces both text and on-screen graphical reports (see Figure 24). The output includes life cycle cost analysis results for ECMs when the user enters first cost information. The detailed information available from the reports and output would be applicable for an ASHRAE Level III, or investment grade audit.

The simuwatt Energy Auditor tool will also export graphs and energy measure information from the OpenStudio suite into a Microsoft Word document from which the user can edit and create the final audit report. simuwatt exports details from the parametric analysis including notes describing the ECM and energy savings tables. 


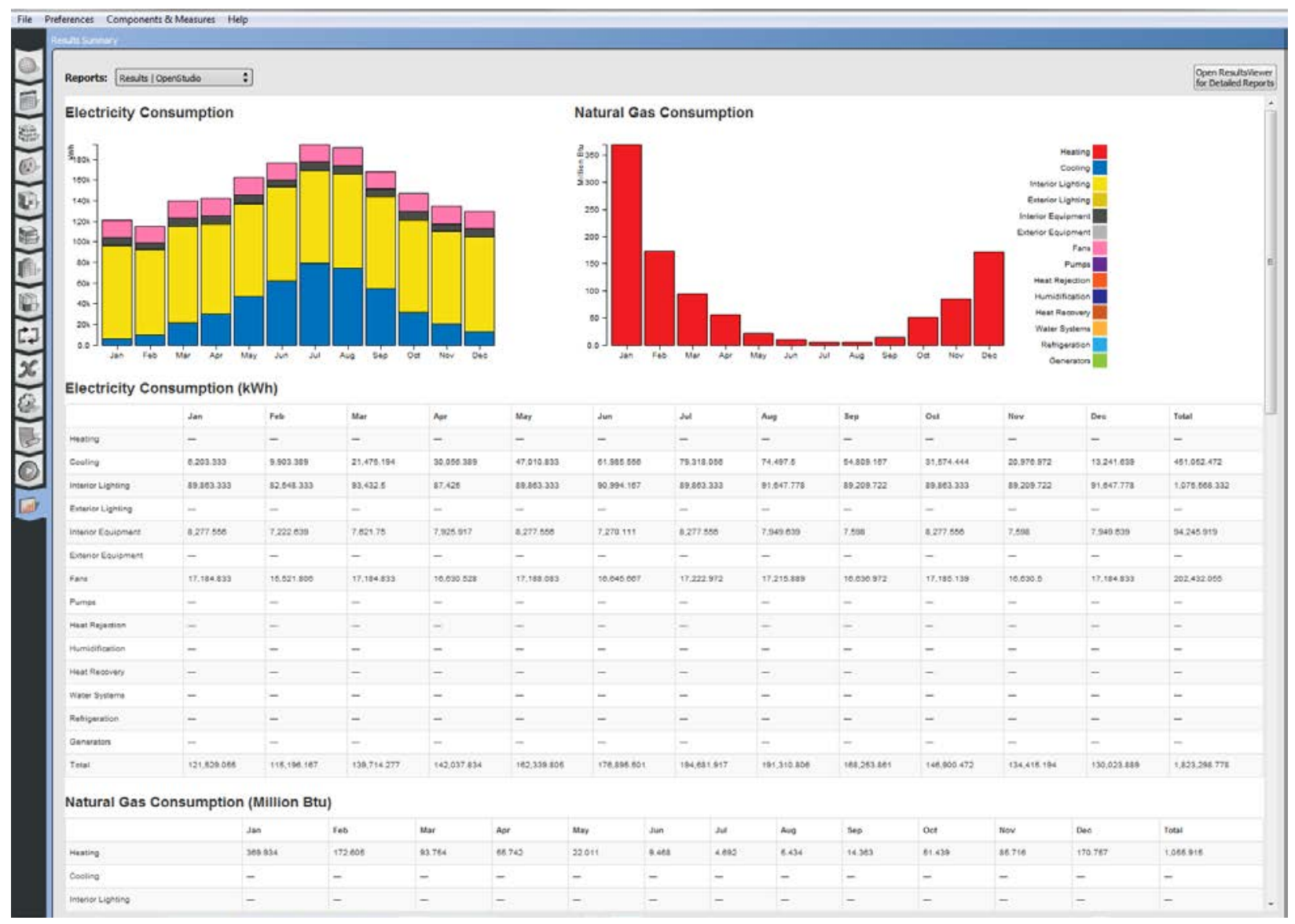

Figure 24. simuwatt model in OpenStudio - Results (https://www.openstudio.net/).

\subsubsection{Commissioning}

The flexibility for setting operating schedules and equipment metrics make simuwatt Energy Auditor a powerful tool for calculating energy savings from implementing operating changes identified through commissioning/retro-commissioning. 


\section{SUMMARY OF SOFTWARE TOOL CAPABILITIES}

\begin{tabular}{|c|c|c|c|c|c|}
\hline Software & EnergyIQ $^{\mathrm{TM}}$ & LEEP & FEDS & eQuest $^{\circledR}$ & simuwatt $^{\mathrm{TM}}$ \\
\hline Software developer & $\begin{array}{l}\text { Lawrence Berkeley } \\
\text { National Lab }\end{array}$ & $\begin{array}{l}\text { Lawrence Berkeley } \\
\text { National Lab }\end{array}$ & $\begin{array}{l}\text { Pacific Northwest } \\
\text { National Lab }\end{array}$ & $\begin{array}{l}\text { James J Hirsch \& } \\
\text { Assoc./Lawrence } \\
\text { Berkeley National Lab }\end{array}$ & $\begin{array}{l}\text { concept3D/National } \\
\text { Renewable Energy Lab }\end{array}$ \\
\hline Website & http://energyiq.lbl.gov/ & http://leep.lbl.gov/ & http://www.pnl.gov/feds/ & http://www.doe2.com/ & http://simuwatt.com/ \\
\hline $\begin{array}{l}\text { Description Summary } \\
\text { from Software } \\
\text { Literature }\end{array}$ & $\begin{array}{l}\text { "Action-oriented" } \\
\text { benchmarking tool for } \\
\text { non-residential } \\
\text { buildings-bridges a } \\
\text { gap by providing a } \\
\text { standardized } \\
\text { opportunity assessment } \\
\text { based on } \\
\text { benchmarking results, } \\
\text { along with } \\
\text { decision-support } \\
\text { information to help } \\
\text { refine action plans. }\end{array}$ & $\begin{array}{l}\text { Helps users to quickly } \\
\text { identify and prioritize } \\
\text { potential energy } \\
\text { efficiency actions in } \\
\text { laboratory facilities. It } \\
\text { does not require users } \\
\text { to have any specialized } \\
\text { knowledge of energy } \\
\text { audits or analysis. }\end{array}$ & $\begin{array}{l}\text { The Facility Energy } \\
\text { Decision System (FEDS) } \\
\text { Windows-based program } \\
\text { requires only minimal } \\
\text { user experience and } \\
\text { input to perform energy } \\
\text { efficiency assessment } \\
\text { screenings as well as } \\
\text { detailed energy retrofit } \\
\text { project analyses across a } \\
\text { wide variety of building } \\
\text { types, from single } \\
\text { buildings to large } \\
\text { multi-building campuses } \\
\text { and installations. }\end{array}$ & $\begin{array}{l}\text { A sophisticated, yet } \\
\text { easy to use building } \\
\text { energy use analysis tool } \\
\text { which provides } \\
\text { professional-level } \\
\text { results with an } \\
\text { affordable level of } \\
\text { effort. This freeware } \\
\text { tool was designed to } \\
\text { allow you to perform } \\
\text { building energy use } \\
\text { simulation. }\end{array}$ & $\begin{array}{l}\text { Replaces the } \\
\text { clipboard-and-pencil } \\
\text { approach of most } \\
\text { building audits with a } \\
\text { package that uses } \\
\text { sophisticated, } \\
\text { comprehensive } \\
\text { computer modeling to } \\
\text { find more potential } \\
\text { energy savings. Tablet } \\
\text { based front-end } \\
\text { working in conjunction } \\
\text { with EnergyPlus energy } \\
\text { simulation modeling } \\
\text { software and } \\
\text { OpenStudio. }\end{array}$ \\
\hline Version reviewed & & & 6.0 .4 & 3.65 build 7163 & Beta \\
\hline Cost & Free & Free & $\begin{array}{l}\text { Free for Federal and } \\
\text { State funded projects }\end{array}$ & Free & $\begin{array}{l}\text { simuwatt will have user } \\
\text { fee/OpenStudio and } \\
\text { EnergyPlus are free }\end{array}$ \\
\hline $\begin{array}{l}\text { Opportunity } \\
\text { Identification or Energy } \\
\text { Simulation }\end{array}$ & $\begin{array}{l}\text { Opportunity } \\
\text { identification }\end{array}$ & $\begin{array}{l}\text { Opportunity } \\
\text { identification }\end{array}$ & $\begin{array}{l}\text { Opportunity } \\
\text { identification/Energy } \\
\text { simulation }\end{array}$ & Energy simulation & Energy simulation \\
\hline $\begin{array}{l}\text { DOE-2/EnergyPlus } \\
\text { based }\end{array}$ & No & No & No & Yes, DOE2 & Yes, EnergyPlus \\
\hline $\begin{array}{l}\text { ENERGY STAR }^{\circledR} \\
\text { Portfolio Manager }^{\circledR} \\
\text { synergistic role }\end{array}$ & $\begin{array}{l}\text { Benchmarking and } \\
\text { data import capability }\end{array}$ & Benchmarking & $\begin{array}{l}\text { Benchmarking and } \\
\text { model calibration }\end{array}$ & $\begin{array}{l}\text { Benchmarking and } \\
\text { model calibration }\end{array}$ & $\begin{array}{l}\text { Benchmarking and } \\
\text { model calibration }\end{array}$ \\
\hline
\end{tabular}




\begin{tabular}{|c|c|c|c|c|c|}
\hline Software & EnergyIQ $^{\mathrm{TM}}$ & LEEP & FEDS & eQuest $^{\circledR}$ & simuwatt $^{\mathrm{TM}}$ \\
\hline $\begin{array}{l}\text { Automatic ECM } \\
\text { suggestions }\end{array}$ & Yes & Yes & Yes & $\begin{array}{l}\text { Parametric analysis } \\
\text { built in }\end{array}$ & $\begin{array}{l}\text { Parametric analysis } \\
\text { built into OpenStudio }\end{array}$ \\
\hline Platform & Web & Web & $\mathrm{PC}$ & $\mathrm{PC}$ & Tablet / Web client / PC \\
\hline Level of effort required & Low & Low & Medium & High & $\begin{array}{l}\text { Medium/High } \\
\text { (EnergyPlus/ } \\
\text { OpenStudio = High) }\end{array}$ \\
\hline Report generation & $\begin{array}{l}\text { Exports output to Excel } \\
\text { spreadsheet or PDF }\end{array}$ & $\begin{array}{l}\text { Viewable on screen or } \\
\text { printed }\end{array}$ & $\begin{array}{l}\text { Text file and Excel } \\
\text { spreadsheet formats }\end{array}$ & Exports output to PDF & $\begin{array}{l}\text { Word document } \\
\text { formatted with sections } \\
\text { for each ECM }\end{array}$ \\
\hline $\begin{array}{l}\text { Engineering expertise } \\
\text { required }\end{array}$ & Minimal & Minimal & Some & High & High \\
\hline Target users & Facility Operators & Facility Operators & $\begin{array}{l}\text { Facility Operators/ } \\
\text { Engineers }\end{array}$ & Consultants/Engineers & Consultants/Engineers \\
\hline Learning curve & Low & Low & Medium & High & $\begin{array}{l}\text { Medium/High } \\
\text { (EnergyPlus/ } \\
\text { OpenStudio = High) }\end{array}$ \\
\hline Assessment type & Preliminary/Level 1 & Preliminary/Level 1 & ASHRAE Level 1 or 2 & ASHRAE Level 2 or 3 & ASHRAE Level 2 or 3 \\
\hline $\begin{array}{l}\text { Investment grade audit } \\
\text { tool }\end{array}$ & No & No & No & Yes & Yes \\
\hline Audit aids provided & None & None & $\begin{array}{l}\text { PDF audit forms for } \\
\text { gathering building } \\
\text { equipment data }\end{array}$ & None & None \\
\hline $\begin{array}{l}\text { ECM estimated energy } \\
\text { savings }\end{array}$ & No & No & Yes & Yes & Yes \\
\hline $\begin{array}{l}\text { ECM estimated } \\
\text { implementation cost }\end{array}$ & No & No & Yes & User Entered & User Entered \\
\hline $\begin{array}{l}\text { ECM estimated energy } \\
\text { cost savings }\end{array}$ & Savings percent range & Savings range & Yes & Yes & Yes \\
\hline $\begin{array}{l}\text { Calculations include } \\
\text { interactive effects } \\
\text { between energy systems }\end{array}$ & Yes & $?$ & Yes & Yes & Yes \\
\hline Life Cycle Cost Analysis & No & No & Yes & Yes & Yes \\
\hline $\begin{array}{l}\text { Estimated life-cycle } \\
\text { savings }\end{array}$ & No & No & Yes & Yes & Yes \\
\hline
\end{tabular}




\begin{tabular}{|c|c|c|c|c|c|}
\hline Software & EnergyIQ $^{\mathrm{TM}}$ & LEEP & FEDS & eQuest $^{\circledR}$ & simuwatt $^{\mathrm{TM}}$ \\
\hline $\begin{array}{l}\text { Estimated life-cycle cost } \\
\text { savings }\end{array}$ & No & No & Yes & Yes & Yes \\
\hline $\begin{array}{l}\text { Savings-to-Investment } \\
\text { Ratio (SIR) }\end{array}$ & $\begin{array}{l}\text { Return On Investment } \\
\text { (ROI) range (high, } \\
\text { medium, low) }\end{array}$ & No & Yes & Yes & Yes \\
\hline Payback period & No & No & Yes & Yes & Yes \\
\hline $\begin{array}{l}\text { Building information } \\
\text { required }\end{array}$ & $\begin{array}{l}\text { Square footage, } \\
\text { building type, location }\end{array}$ & $\begin{array}{l}\text { Square footage, } \\
\text { building type, location }\end{array}$ & $\begin{array}{l}\text { Detailed information on } \\
\text { building walls and roof } \\
\text { construction }\end{array}$ & $\begin{array}{l}\text { Detailed information on } \\
\text { building walls and roof } \\
\text { construction }\end{array}$ & $\begin{array}{l}\text { Detailed information on } \\
\text { building walls and roof } \\
\text { construction }\end{array}$ \\
\hline $\begin{array}{l}\text { Building energy/water } \\
\text { information required }\end{array}$ & $\begin{array}{l}\text { Annual energy } \\
\text { consumption by fuel } \\
\text { type }\end{array}$ & $\begin{array}{l}\text { Annual energy } \\
\text { consumption by fuel } \\
\text { type }\end{array}$ & $\begin{array}{l}\text { Annual energy } \\
\text { consumption by fuel } \\
\text { type, annual costs }\end{array}$ & $\begin{array}{l}\text { Monthly energy } \\
\text { consumption by fuel } \\
\text { type for model } \\
\text { calibration }\end{array}$ & $\begin{array}{l}\text { Monthly energy } \\
\text { consumption by fuel } \\
\text { type for model } \\
\text { calibration }\end{array}$ \\
\hline $\begin{array}{l}\text { Building equipment } \\
\text { information required }\end{array}$ & $\begin{array}{l}\text { Basic info: Lighting, } \\
\text { HVAC, motors, } \\
\text { electrical and } \\
\text { mechanical systems }\end{array}$ & $\begin{array}{l}\text { Basic info: Lighting, } \\
\text { HVAC, motors, } \\
\text { electrical and } \\
\text { mechanical systems, } \\
\text { lab hoods and } \\
\text { equipment }\end{array}$ & $\begin{array}{l}\text { Information on HVAC } \\
\text { systems, lighting, } \\
\text { internal loads, and } \\
\text { operating schedules }\end{array}$ & $\begin{array}{l}\text { Detailed information on } \\
\text { HVAC systems, } \\
\text { lighting, internal loads, } \\
\text { and operating schedules }\end{array}$ & $\begin{array}{l}\text { Detailed information on } \\
\text { HVAC systems, } \\
\text { lighting, internal loads, } \\
\text { and operating schedules }\end{array}$ \\
\hline $\begin{array}{l}\text { Ability to bundle ECMs } \\
\text { for combined savings }\end{array}$ & No & No & Yes & Yes & Yes \\
\hline $\begin{array}{l}\text { Applicable building } \\
\text { types }\end{array}$ & Non-residential & Laboratories & Civilian and Military & All & All \\
\hline
\end{tabular}




\section{REFERENCES}

Baechler, Michael (Pacific Northwest National Laboratory), and Cindy Strecker, PE and Jennifer Shafer (Portland Energy Conservation, Inc.), A Guide to Energy Audits, PNNL-20956, http://www.pnnl.gov/main/publications/external/technical_reports/pnnl-20956.pdf, September 2011.

HR 6, 110 Congress, Energy Independence and Security Act of 2007, http://www.gpo.gov/fdsys/pkg/BILLS-110hr6enr/pdf/BILLS-110hr6enr.pdf.

Lawrence Berkeley National Laboratory, Environmental Energy Technologies Division, EnergyIQ homepage, http://energyiq.lbl.gov/.

Lawrence Berkeley National Laboratory, Environmental Energy Technologies Division, EnergyIQ online User Guide, https://sites.google.com/a/lbl.gov/energyiq/home.

Lawrence Berkeley National Laboratory, Environmental Energy Technologies Division, Laboratory Energy Efficiency (LEEP) homepage: http://leep.lbl.gov/.

National Institute of Building Sciences, FEMP02 Planning an Energy Assessment for Federal Facilities, Whole Building Design Guide, http://www.wbdg.org/education/femp02.php, published September 2008.

Pacific Northwest National Laboratory, Facility Energy Decision System, http://www.pnl.gov/feds/, published December, 2011.

Pacific Northwest National Laboratory, Facility Energy Decision System (FEDS) User's Guide, Release 6.0, published September 2008.

Presidential Memorandum, Leadership on Energy Management, http://www.whitehouse.gov/the-press-office/2013/12/05/presidential-memorandum-federal-leadership -energy-management, published December 5, 2013.

U.S. Department of Energy Facility Energy Management Guidelines and Criteria for Energy and Water Evaluations in Covered Facilities (42 U.S.C. 8253 Subsection (f), Use of Energy and Water Efficiency Measures in Federal Buildings) http://www1.eere.energy.gov/femp/pdfs/eisa s432 guidelines.pdf, published November 25, 2008.

U.S. Environmental Protection Agency, Labs21 Benchmarking Tool, http://labs21benchmarking.lbl.gov/, published November 13, 2013.

U.S. Department of Energy, eQUEST the Quick Energy Simulation Tool, http://www.doe2.com/equest/, published 2009.

U.S. Department of Energy, National Renewable Energy Laboratory, Office of Energy Efficiency \& Renewable Energy, EnergyPlus website, http://www.energyplus.gov/, published October 30, 2013.

U.S. Department of Energy, National Renewable Energy Laboratory, Office of Energy Efficiency and Renewable Energy, NREL Brings Precision, Savings to Energy Audits, http://www.nrel.gov/news/features/feature_detail.cfm/feature_id=4300, published October 22, 2013.

U.S. Department of Energy, National Renewable Energy Laboratory, Office of Energy Efficiency and Renewable Energy, OpenStudio website, https://openstudio.nrel.gov/, published July 1, 2014

U.S. Department of Energy, National Renewable Energy Laboratory, Office of Energy Efficiency and Renewable Energy, simuwatt website, http://simuwatt.com/. 